\title{
Model Reduction for Inverters with Current Limiting and Dispatchable Virtual Oscillator Control
}

\author{
Olaoluwapo Ajala, Member, IEEE, Minghui Lu, Member, IEEE, Brian Johnson, Member, IEEE, \\ Sairaj Dhople, Member, IEEE, and Alejandro Domínguez-García, Senior Member, IEEE
}

\begin{abstract}
This paper outlines reduced-order models for grid-forming virtual-oscillator-controlled inverters with nested current- and voltage-control loops, and current-limiting action for over-current protection. While a variety of model-reduction methods have been proposed to tame complexity in inverter models, previous efforts have not included the impact of currentreference limiting. In addition to acknowledging the currentlimiting action, the reduced-order models we outline are tailored to networks with resistive and inductive interconnecting lines. Our analytical approach is centered on a smooth function approximation for the current-reference limiter, participation factor analysis to identify slow- and fast-varying states, and singular perturbation to systematically eliminate the fast states. Computational benefits and accuracy of the reduced-order models are benchmarked via numerical simulations that compare them to higher-order averaged and switched models.
\end{abstract}

\section{INTRODUCTION}

$\mathbf{T}$ HE increasing deployment of inverter-based resources has altered the dynamic characteristics of electric grids. In this context, there has been significant attention, in recent years, on replacing synchronous power generators with gridforming (GFM) inverter-based counterparts which, in the absence of synchronous generators, can sustain system voltages and frequency [1], [2]. Examples of such GFM control strategies include droop [3]-[5], virtual synchronous machines [6][10], and virtual oscillator control (VOC) [11]-[25].

Motivated by the fact that the VOC strategy is a globally stabilizing control strategy that is able to deal with higherorder harmonics [26], this paper leverages the theory of singular perturbation [27] to outline reduced-order models for a recently proposed variant of VOC called dispatchable virtual oscillator control (dVOC). The controller leverages the nonlinear dynamics of the Andronov-Hopf oscillator (AHO) to facilitate synchronization in low-inertia settings, and it also features functionality to respond to power and voltage setpoints [16]-[25]. A schematic representation of the threephase GFM inverter we examine is sketched in Fig. 1. The constituent subsystems in the model include: i) the dVOC module that generates voltage and frequency setpoints; ii) an $L C L$ filter; iii) a proportional-integral current controller with a current-reference limiter; and iv) a proportional-integral voltage controller that includes integrator anti-windup control ${ }^{1}$ Two challenges immediately surface when considering the

\footnotetext{
${ }^{1}$ The structure depicted in Fig. 1 (nested voltage- and current-control loops and current-reference limiting) applies universally to GFM inverters. Distinguishing attributes are introduced by the outermost controller that determines voltage and frequency setpoints. In this work, we assume the outermost controller is implemented via dVOC.
}

prospect of leveraging such models for system-level analysis. First, such models have multiple dynamic states (12 in this particular instance) which presents significant challenges to modeling dynamics of large networks of such inverters with limited computational burden. Second, the nonlinear elements sprinkled throughout the models (stemming from reference-frame transformations, current-reference limits, nonlinear GFM control strategies) present a non-trivial analytical impediment. Notably, these challenges hold true for a broad class of GFM inverter control methods going beyond the dVOC implementation we focus on.

Our main contribution is the development of reduced-order models for the dVOC flavor of GFM inverters that systematically acknowledge all pertinent nonlinearities in the model, particularly, the impact of the current-reference limiter. The current-reference limiter is a key element in the overall control scheme for GFM inverters since it addresses over-currents that would appear otherwise during faults and voltage sags [28][30]. It is typically realized with saturation functions that are incompatible with analytical approaches for model reduction. We circumvent this challenge with a smooth-function approximation that carries through the analytical developments. While reduced-order models have been proposed for GFM inverters (we review prior art shortly), to the best of our knowledge, these do not acknowledge current-reference limiters.

A majority of related literature in model reduction for GFM inverters is centered on droop control [31]-[35]. This is understandable since droop control is one of the earliest proposed GFM control strategies. There are recent efforts-albeit significantly fewer-focused on model reduction for other GFM controls, including virtual synchronous machines [36] and VOC [37]. These prior efforts have not considered the impact of the current-reference limiter in deriving reducedorder models. This singular aspect underscores the main contribution of our effort. Furthermore, we utilize participationfactor analysis to tease out distinct reduced-order models for dominantly resistive and dominantly inductive interconnecting lines. Such a systematic classification is particularly relevant, since it is well recognized that line attributes have non-trivial impact on system dynamics in low-inertia settings [18].

The remainder of this paper is organized as follows. Preliminaries are discussed in Section III, the full-order model is overviewed in Section III, and reduced-order models are derived in Section IV] Numerical results comparing the reducedorder models with full-order averaged and switched models are presented in Section $\mathrm{V}$, and concluding remarks are given in Section VI 


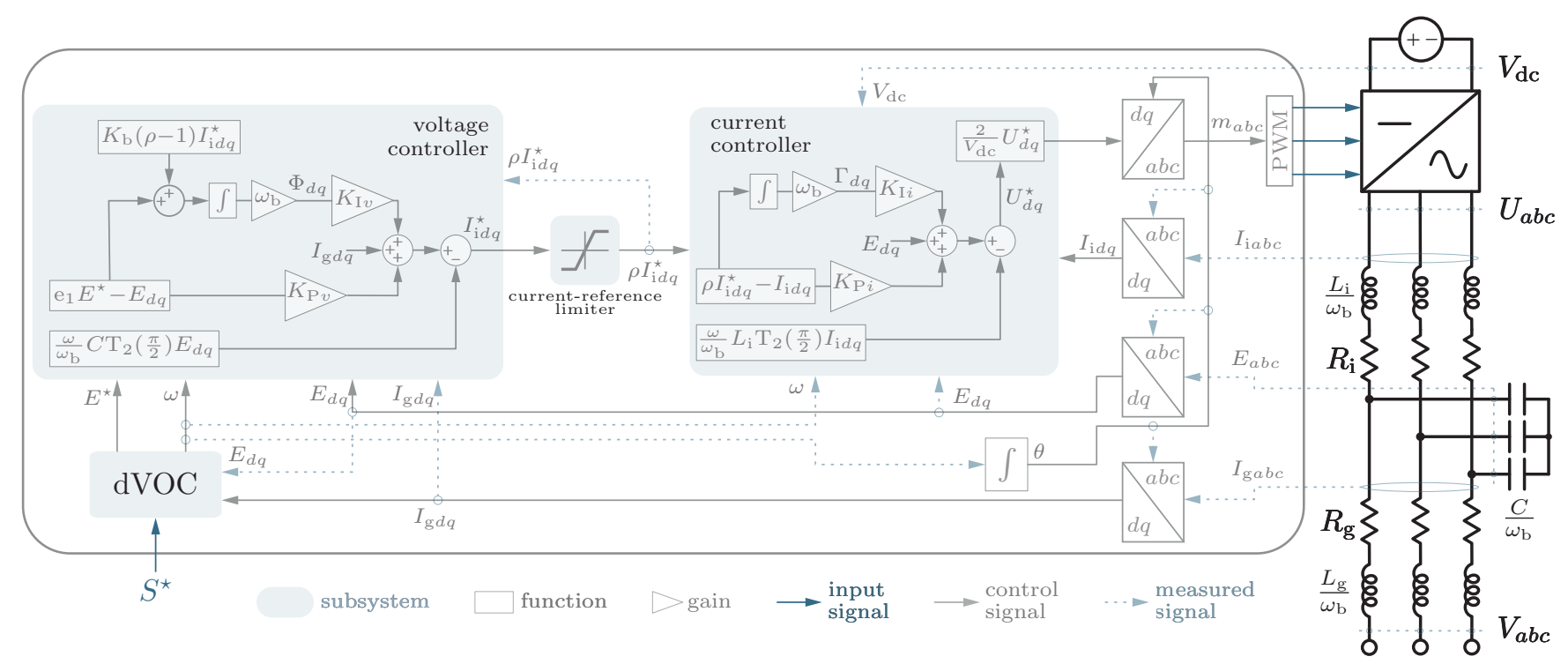

Fig. 1: Schematic representation of the GFM inverter per-unit dynamical model with dVOC.

\section{PREliminaries}

\section{A. Reference-frame Transformations \& Notation}

Consider the three-phase signal $f_{a b c}=\left[f_{a}, f_{b}, f_{c}\right]^{\top}$, where $f_{a}, f_{b}$, and $f_{c}$ form a balanced three-phase set. Let $\omega_{\mathrm{b}}$ and $\omega(t)$ denote the nominal angular frequency and the GFM inverter's angular frequency, in $\mathrm{rad} \mathrm{s}^{-1}$, respectively, and define

$$
\theta(t)=\int_{0}^{t} \omega(\tau) d \tau+\theta(0), \quad \delta(t)=\theta(t)-\omega_{\mathrm{b}} t .
$$

Let $f_{D Q}=\left[f_{D}, f_{Q}\right]^{\top}$ and $f_{d q}=\left[f_{d}, f_{q}\right]^{\top}$ denote transformations of $f_{a b c}$ to reference frames rotating at angular frequencies $\omega_{\mathrm{b}}$ and $\omega(t)$, respectively. We define the $D Q$ and $d q$ transformations of $f_{a b c}$ as follows:

$$
f_{D Q}=\mathrm{T}_{1}\left(\omega_{\mathrm{b}} t\right) f_{a b c}, \quad f_{d q}=\mathrm{T}_{1}(\theta) f_{a b c},
$$

where transformation matrix $\mathrm{T}_{1}(\cdot)$ is defined as:

$$
\mathrm{T}_{1}(\alpha)=\frac{2}{3}\left[\begin{array}{ccc}
\cos \alpha & \cos \left(\alpha-\frac{2 \pi}{3}\right) & \cos \left(\alpha+\frac{2 \pi}{3}\right) \\
-\sin \alpha & -\sin \left(\alpha-\frac{2 \pi}{3}\right) & -\sin \left(\alpha+\frac{2 \pi}{3}\right)
\end{array}\right] .
$$

Signals in the $D Q$ and $d q$ reference frames are related via

$$
f_{d q}=\mathrm{T}_{2}(\delta) f_{D Q}
$$

where rotation matrix $\mathrm{T}_{2}(\cdot)$ is defined as

$$
\mathrm{T}_{2}(\alpha)=\left[\begin{array}{cc}
\cos \alpha & \sin \alpha \\
-\sin \alpha & \cos \alpha
\end{array}\right]
$$

The $2 \times 2$ identity matrix is denoted by $\mathrm{I}$; $\mathrm{e}_{1}=[1,0]^{\top}$ and $\mathrm{e}_{2}=[0,1]^{\top}$ are the standard basis vectors.

\section{B. Participation Factors}

For the linear system $\dot{x}=A x$, where $A \in \mathbb{R}^{n \times n}, x \in \mathbb{R}^{n}$, let $r_{i j}$ and $l_{i j}$ denote the $i$-th entries of the right and left eigenvectors associated with the $j$-th eigenvalue of $A$, respectively. The participation of the $i$-th element of $x$ in the $j$-th eigenvalue of $A$ is quantified by

$$
\frac{\left|r_{i j}\right|\left|l_{i j}\right|}{\sum_{i=1}^{n}\left|r_{i j}\right|\left|l_{i j}\right|}
$$

and is called the participation factor [38]. Hereafter, participation factors are normalized using their maximum values.

\section{AVERAGED Full-ORder GFM INVERTER MOdEL}

In this section, we present the averaged full-order dynamical model for GFM inverters covering all control- and physicallayer subsystems. In subsequent developments, we use perunit normalization (see, e.g., [39]) with the rated three-phase power, $S_{r}$, rated line-to-line voltage (RMS), $E_{r}$, and nominal system frequency, $\omega_{\mathrm{b}}$, serving as base quantities for power, voltage, and frequency, respectively. This facilitates a unified and systematically normalized transcription of all parameters and variables in the dynamic models.

Table II summarizes numerical per-unit values for all the controller and filter parameters adopted in this work, with respective expressions for their base quantities enumerated. Controller and filter parameters are designed assuming $S_{r}=$ $1500 \mathrm{VA}, E_{r}=208 \mathrm{~V}, \omega_{\mathrm{b}}=2 \pi 60 \mathrm{rads}^{-1}$, and a switching frequency of $10 \mathrm{kHz}$. We discuss the design choices of pertinent parameters alongside the overview of each subsystem.

\section{A. The Dispatchable Virtual Oscillator Controller}

Let $P$ and $Q$ denote the active- and reactive-power delivered to the grid at the filter-capacitance terminals, and define $S=$ $[P, Q]^{\top}$. Furthermore, let $E^{\star}, P^{\star}$, and $Q^{\star}$ denote references for the voltage magnitude, active power, and reactive power, respectively, and define $S^{\star}=\left[P^{\star}, Q^{\star}\right]^{\top}$. Following from the definitions of $\theta$ and $\omega$ in Section II-A the dynamics of frequency and voltage-magnitude references are

$$
\begin{gathered}
\dot{\theta}=\omega=\omega_{\mathrm{b}}+\frac{\omega_{\mathrm{b}} \kappa_{1}}{\left(E^{\star}\right)^{2}} \mathrm{e}_{1}^{\top} \mathrm{T}_{2}\left(\psi-\frac{\pi}{2}\right)\left(S^{\star}-S\right), \\
\dot{E}^{\star}=\frac{\omega_{\mathrm{b}} \kappa_{1}}{E^{\star}} \mathrm{e}_{2}^{\top} \mathrm{T}_{2}\left(\psi-\frac{\pi}{2}\right)\left(S^{\star}-S\right) \\
+\omega_{\mathrm{b}} \kappa_{2}\left(E_{\mathrm{b}}^{2}-\left(E^{\star}\right)^{2}\right) E^{\star},
\end{gathered}
$$

where $E_{\mathrm{b}}$ denotes the nominal inverter voltage magnitude, $\kappa_{1}$ is the synchronization gain, and $\kappa_{2}$ is the voltage-amplitude 
TABLE I: Model Parameters and Base Values.

\begin{tabular}{|c|c|c|c|c|c|}
\hline Symbol & Description & Value & Unit & Base value & Base unit \\
\hline$\psi$ & rotation angle & $\frac{\pi}{4}$ & $\mathrm{rad}$ & \multirow{2}{*}{ N/A } & \multirow{2}{*}{ N/A } \\
\hline$\varepsilon$ & $\begin{array}{l}\text { saturation-function } \\
\text { parameter }\end{array}$ & 0.1 & N/A & & \\
\hline$E_{\mathrm{b}}$ & $\begin{array}{l}\text { nominal voltage } \\
\text { magnitude (peak) }\end{array}$ & 1 & $\mathrm{pu}$ & $\frac{E_{r} \sqrt{2}}{\sqrt{3}}$ & V \\
\hline$I_{\max }$ & $\begin{array}{l}\text { peak current } \\
\text { limit }\end{array}$ & 1.2 & $\mathrm{pu}$ & $\frac{S_{r} \sqrt{2}}{E_{r} \sqrt{3}}$ & A \\
\hline$L_{\mathrm{i}}$ & $\begin{array}{l}\text { inverter-side } \\
\text { inductance }\end{array}$ & 0.0196 & $\mathrm{pu}$ & \multirow{3}{*}{$\frac{E_{r}^{2}}{S_{r} \omega_{\mathrm{b}}}$} & \multirow{3}{*}{$\mathrm{H}$} \\
\hline \multirow{2}{*}{$L_{\mathrm{g}}$} & $\begin{array}{l}\text { grid-side } \\
\text { inductance }\end{array}$ & 0.0196 & $\mathrm{pu}$ & & \\
\hline & $\begin{array}{l}\text { grid-side }+ \text { line } \\
\text { inductance }\end{array}$ & 0.037 & $\mathrm{pu}$ & & \\
\hline$C$ & $\begin{array}{l}\text { filter } \\
\text { capacitance }\end{array}$ & 0.1086 & $\mathrm{pu}$ & $\frac{S_{r}}{E_{r}^{2} \omega_{\mathrm{b}}}$ & $\mathrm{F}$ \\
\hline$R_{\mathrm{i}}$ & $\begin{array}{l}\text { inverter-side } \\
\text { resistance }\end{array}$ & 0.0139 & $\mathrm{pu}$ & \multirow{5}{*}{$\frac{E_{r}^{2}}{S_{r}}$} & \multirow{5}{*}{$s$} \\
\hline \multirow{2}{*}{$R_{\mathrm{g}}$} & $\begin{array}{l}\text { grid-side } \\
\text { resistance }\end{array}$ & 0.0139 & $\mathrm{pu}$ & & \\
\hline & $\begin{array}{l}\text { grid-side }+ \text { line } \\
\text { resistance }\end{array}$ & 0.0313 & $\mathrm{pu}$ & & \\
\hline$K_{\mathrm{b}}$ & $\begin{array}{l}\text { anti-windup } \\
\text { gain }\end{array}$ & 0.0347 & $\mathrm{pu}$ & & \\
\hline$K_{\mathrm{P} i}$ & $\begin{array}{l}\text { proportional } \\
\text { gain }\end{array}$ & 0.9817 & $\mathrm{pu}$ & & \\
\hline$K_{\mathrm{I} i}$ & integral gain & 0.6944 & $\mathrm{pu}$ & \multirow{2}{*}{$\frac{E_{r}^{2} \omega_{\mathrm{b}}}{S_{r}}$} & \multirow{2}{*}{$\mathrm{F}^{-1}$} \\
\hline$\kappa_{1}$ & $\begin{array}{l}\text { synchronization } \\
\text { gain }\end{array}$ & 0.0033 & $\mathrm{pu}$ & & \\
\hline$K_{\mathrm{P} v}$ & $\begin{array}{l}\text { proportional } \\
\text { gain }\end{array}$ & 1.4476 & $\mathrm{pu}$ & $\frac{S_{r}}{E_{r}^{2}}$ & $\Omega^{-1}$ \\
\hline$K_{\mathrm{I} v}$ & integral gain & 10.2944 & $\mathrm{pu}$ & $\frac{S_{r} \omega_{\mathrm{b}}}{E_{r}^{2}}$ & $\mathrm{H}^{-1}$ \\
\hline$\omega_{\mathrm{bw}, \mathrm{i}}$ & $\begin{array}{l}\text { current-loop } \\
\text { bandwidth }\end{array}$ & 50 & $\mathrm{pu}$ & \multirow{2}{*}{$\omega_{\mathrm{b}}$} & \multirow[t]{2}{*}{$\operatorname{rads}^{-1}$} \\
\hline$\omega_{\mathrm{bw}, \mathrm{v}}$ & $\begin{array}{l}\text { voltage-loop } \\
\text { bandwidth }\end{array}$ & 13.3333 & $\mathrm{pu}$ & & \\
\hline$\kappa_{2}$ & $\begin{array}{l}\text { voltage-amplitude } \\
\text { control gain }\end{array}$ & 0.0796 & $\mathrm{pu}$ & $\frac{3 \omega_{\mathrm{b}}}{2 E_{r}^{2}}$ & $\operatorname{rad~s}^{-1} \mathrm{~V}^{-2}$ \\
\hline
\end{tabular}

control gain. Furthermore, $\psi \in[0,2 \pi)$ denotes the rotation angle of the controller, which is typically tuned based on the $\frac{R}{X}$ ratio of interconnecting lines. For instance, $\psi=\frac{\pi}{2}$ is well suited for inductive transmission lines since it yields active power-frequency and reactive power-voltage droop in steady state [16]. The model $(7 \mathrm{a})-(7 \mathrm{~b})$ is built from cycleaveraged dynamics of the Andronov-Hopf oscillator in polar coordinates ${ }^{2}$

Rationale for choice of $\kappa_{1}, \kappa_{2}$, and $\psi$ : Numerical values for $\kappa_{1}$ and $\kappa_{2}$ listed in Table I I ensure that the output voltage and frequency are approximately $0.95 \mathrm{pu}$ and $59.5 \mathrm{~Hz}$, respectively, when $S=[1,1]^{\top}$ (full load) and $S^{\star}=[0,0]^{\top}$. In this context, the output voltage and frequency will return to their nominal values when we set $S^{\star}=[1,1]^{\top}$ (see [16], [25] for details). The choice of rotation angle $\psi=\frac{\pi}{4}$ ensures a level of generality by preserving cross-coupling between active power, reactive power, frequency, and voltage.

\footnotetext{
${ }^{2}$ The dynamical model for the unforced Andronov-Hopf oscillator in polar coordinates takes the general form: $\dot{r}=r\left(1-r^{2}\right), \dot{\theta}=\omega_{\mathrm{b}}$. Suitably tailoring this to acknowledge inputs, leveraging periodic-averaging theory, and including pertinent scaling factors, yields $7 \mathrm{a}-\mathrm{ab}$.
}

\section{B. The LCL Filter}

Let $U_{d q}, E_{d q}$, and $V_{D Q}$ denote the filter's inverter-side, capacitor, and grid-side voltages, respectively. Let $I_{\mathrm{i} d q}$ and $I_{\mathrm{g} d q}$ denote the filter's inverter-side and grid-side currents, respectively. The filter dynamics are captured by

$$
\begin{gathered}
\dot{I}_{\mathrm{i} d q}=\left(\omega \mathrm{T}_{2}\left(\frac{\pi}{2}\right)-\omega_{\mathrm{b}} \frac{R_{\mathrm{i}}}{L_{\mathrm{i}}} \mathrm{I}\right) I_{\mathrm{i} d q}+\frac{\omega_{\mathrm{b}}}{L_{\mathrm{i}}}\left(U_{d q}-E_{d q}\right), \\
\dot{E}_{d q}=\omega \mathrm{T}_{2}\left(\frac{\pi}{2}\right) E_{d q}+\frac{\omega_{\mathrm{b}}}{C}\left(I_{\mathrm{i} d q}-I_{\mathrm{g} d q}\right), \\
\dot{I}_{\mathrm{g} d q}=\left(\omega \mathrm{T}_{2}\left(\frac{\pi}{2}\right)-\omega_{\mathrm{b}} \frac{R_{\mathrm{g}}}{L_{\mathrm{g}}} \mathrm{I}\right) I_{\mathrm{g} d q} \\
\quad+\frac{\omega_{\mathrm{b}}}{L_{\mathrm{g}}}\left(E_{d q}-\mathrm{T}_{2}(\delta) V_{D Q}\right),
\end{gathered}
$$

where $L_{\mathrm{i}}, L_{\mathrm{g}}$, and $C$ denote the inverter-side inductance, gridside inductance, and capacitance of the $L C L$ filter, respectively; $R_{\mathrm{i}}$ and $R_{\mathrm{g}}$ denote the non-ideal series resistances associated with the inverter- and grid-side inductors, respectively.

Rationale for choice of $L_{\mathrm{g}}, L_{\mathrm{i}}$, and $C$ : One well-established approach for designing the LCL filter involves selecting a resonant frequency that is between ten times the value of the grid frequency (60 $\mathrm{Hz}$ in this case) and half the value of the switching frequency $(10 \mathrm{kHz}$ in this case) [40]. For a given resonant frequency $(1.8 \mathrm{kHz}$ in our design), picking the inverter-side inductance to be equal to the grid-side inductance ensures the smallest capacitive reactive power [41]. These design considerations yield the choice of values for $L_{\mathrm{g}}, L_{\mathrm{i}}$, and $C$ reported in Table II The parasitic resistances follow from the hardware prototype realization discussed in [16].

Remark 1 (Defining Active- and Reactive-power Outputs). With the filter currents and voltages formally annotated, the active- and reactive-power outputs measured at the filter capacitors can be expressed as:

$$
P=E_{d q}^{\top} I_{\mathrm{g} d q}, \quad Q=E_{d q}^{\top} \mathrm{T}_{2}\left(-\frac{\pi}{2}\right) I_{\mathrm{g} d q} .
$$

\section{The Current-reference Limiter}

As depicted in Fig. 1, the current controller acts on a reference command, denoted by $I_{\mathrm{i} d q}^{\star}$, which is generated by the voltage controller (to be described in detail later). As a first step, the magnitude of this reference is saturated to the inverter peak-current limit, $I_{\max }$. In the literature, this has been accomplished with the following saturation function [19], [42]:

$$
\min \left(1, \frac{I_{\max }}{\left\|I_{\mathrm{i} d q}^{\star}\right\|_{2}}\right) I_{\mathrm{i} d q}^{\star} .
$$

For analytical convenience, we model the current-reference limiting operation via the product $\rho I_{\mathrm{i} d q}^{\star}$, where $\rho$ is given by:

$$
\rho=-\varepsilon \ln \left(\exp \left(\frac{-1}{\varepsilon}\right)+\exp \left(\frac{-I_{\max }}{\varepsilon\left\|I_{\mathrm{i} d q}^{\star}\right\|_{2}}\right)\right) .
$$

The $\min (\cdot, \cdot)$ function in 10 can be approximated by $\rho$ for small values of the saturation-function parameter, $\varepsilon$.

Rationale for choice of $I_{\max }$ and $\varepsilon$ : The choice of $I_{\max }$ in Table I follows [42], which has espoused limits in this range for GFM inverters. The choice of $\varepsilon$ ensures a close match of the approximation $\rho$ to the $\min (\cdot, \cdot)$ function. (See Fig. 2, ) 


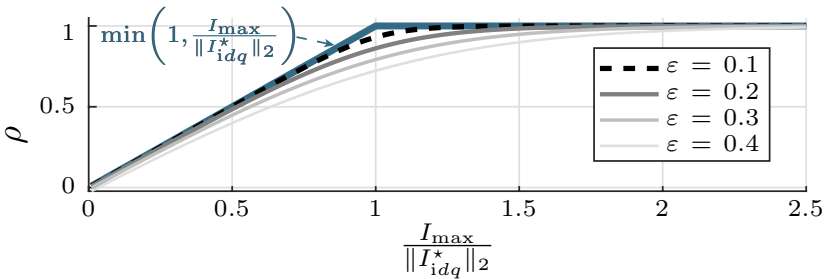

Fig. 2: Approximations of the $\min (\cdot, \cdot)$ function $(10)$ with $\rho$ (11) for $\varepsilon=0.1,0.2,0.3$, and 0.4 .

\section{The Voltage Controller}

The voltage controller acts on the terminal-voltage reference, denoted by $E^{\star}$, which is generated by the dVOC module and yields the current-control reference command, $I_{\mathrm{i} d q}^{\star}$. Let $\Phi_{d q}$ denote the state variable of the voltage controller. The dynamics of the voltage controller are governed by

$$
\begin{aligned}
\dot{\Phi}_{d q} & =\omega_{\mathrm{b}}\left(\mathrm{e}_{1} E^{\star}-E_{d q}\right)+\omega_{\mathrm{b}} K_{\mathrm{b}}(\rho-1) I_{\mathrm{i} d q}^{\star}, \\
\widehat{\rho} I_{\mathrm{i} d q}^{\star} & =\frac{K_{\mathrm{P} v}}{\omega_{\mathrm{b}}} \dot{\Phi}_{d q}+K_{\mathrm{I} v} \Phi_{d q}+I_{\mathrm{g} d q}-\frac{\omega}{\omega_{\mathrm{b}}} C \mathrm{~T}_{2}\left(\frac{\pi}{2}\right) E_{d q},
\end{aligned}
$$

where $\widehat{\rho}=1+K_{\mathrm{P} v} K_{\mathrm{b}}(\rho-1), K_{\mathrm{P} v}$ and $K_{\mathrm{I} v}$ denote the voltage controller's proportional and integrator gains, respectively, and $K_{\mathrm{b}}$ denotes the integrator anti-windup gain. In effect, 12a and (12b) constitute a proportional-integral (PI) control system with reference $E^{\star}$, controlled signal $E_{d q}$, and control input $I_{\mathrm{i} d q}^{\star}$. The loop includes a feed-forward compensation term, $I_{\mathrm{g} d q}-\frac{\omega}{\omega_{\mathrm{b}}} C \mathrm{~T}_{2}\left(\frac{\pi}{2}\right) E_{d q}$, and an integrator anti-windup term $K_{\mathrm{b}}(\rho-1) I_{\mathrm{i} d q}^{\star}$ [42] [43, pp. 245-262].

Rationale for choice of $K_{\mathrm{P} v}, K_{\mathrm{I} v}$, and $K_{\mathrm{b}}$ : The bandwidth of the current-control loop (which we denote by $\omega_{\mathrm{bw}, \mathrm{i}}$ ) is typically one-tenth to one-fifth of the switching frequency, and that of the voltage-control loop (which we denote by $\left.\omega_{\mathrm{bw}, \mathrm{v}}\right)$ is multiple times slower for time-scale separation. The PI gains for the controller are set as $K_{\mathrm{P} v}=\omega_{\mathrm{bw}, \mathrm{v}} C$ and $K_{\mathrm{I} v}=2 K_{\mathrm{P} v} \omega_{\mathrm{bw}, \mathrm{v}}^{2} / \omega_{\mathrm{bw}, \mathrm{i}}$ to yield an approximately first-order response [43, pp. 253-257]. A manual trial-and-error process is used to tune the value of $K_{\mathrm{b}}$.

\section{E. Current Controller}

Let $\Gamma_{d q}$ denote the state variable corresponding to the current controller, and $U_{d q}^{\star}$ denote the output of the current controller. Note that $U_{d q}^{\star}$ generates the PWM reference signals for the inverter. The dynamics of the current controller are

$$
\begin{aligned}
& \dot{\Gamma}_{d q}=\omega_{\mathrm{b}}\left(\rho I_{\mathrm{i} d q}^{\star}-I_{\mathrm{i} d q}\right), \\
& U_{d q}^{\star}=\frac{K_{\mathrm{P} i}}{\omega_{\mathrm{b}}} \dot{\Gamma}_{d q}+K_{\mathrm{I} i} \Gamma_{d q}+E_{d q}-\frac{\omega}{\omega_{\mathrm{b}}} L_{\mathrm{i}} \mathrm{T}_{2}\left(\frac{\pi}{2}\right) I_{\mathrm{i} d q},
\end{aligned}
$$

where $K_{\mathrm{P} i}$ and $K_{\mathrm{I} i}$ are the current-controller proportional and integrator gains, respectively. In effect, $13 \mathrm{a}-113 \mathrm{~b}$ close the loop around the inverter-side inductor current, $I_{\mathrm{i} d q}$, with a PI loop that acts on a saturated version of the current reference, $\rho I_{\mathrm{i} d q}^{\star}$. The feed-forward compensation term, $E_{d q}-$ $\frac{\omega}{\omega_{\mathrm{b}}} L_{\mathrm{i}} \mathrm{T}_{2}\left(\frac{\pi}{2}\right) I_{\mathrm{i} d q}$, in $13 \mathrm{~b}$ enhances disturbance rejection 43 p. 219].

Rationale for choice of $K_{\mathrm{P} i}$ and $K_{\mathrm{I} i}$ : The PI gains are set as $K_{\mathrm{P} i}=\omega_{\mathrm{bw}, \mathrm{i}} L_{\mathrm{i}}$ and $K_{\mathrm{I} i}=\omega_{\mathrm{bw}, \mathrm{i}} R_{\mathrm{i}}$ to yield an approximately first-order response from reference to output [43, p. 247].

\section{F. The Three-phase Inverter}

The three-phase line-neutral voltage at the inverter switch terminals is captured by $U_{a b c}=\frac{V_{\mathrm{dc}}}{2} m_{a b c}$, where $m_{a b c}$ denotes the pulse-width modulation (PWM) signals and $V_{\mathrm{dc}}$ is the perunitized dc-side voltage (see [43], pp. 115-126 for details). With the control architecture sketched in Fig. 1, it emerges that the averaged voltages at the inverter switched terminals in the $d q$ reference frame are given by: $U_{d q}=U_{d q}^{\star}$.

\section{The PER-Unit ReduCED-ORDER MOdels}

In this section, we present the main results of this work, namely: reduced-order models for GFM inverters with dVOC acknowledging the current-reference limiter. The reducedorder models are sketched in Figs. $3 \mathrm{a}$ and $3 \mathrm{~b}$, for inverters with inductive and resistive interconnecting lines, respectively. Compared to Fig. 1, in both cases, the dynamics of the currentand voltage-control loops are abstracted, as are the dynamics corresponding to the inverter-side inductance, $L_{\mathrm{i}}$, and filter capacitance, $C$. The impact of the current-reference limiter is preserved through an algebraic constraint in both cases.

We begin with a discussion on how to determine the dimension of the reduced-order models. Subsequently, we discuss the derivation of the reduced-order models and consider the special case without the current-reference limiter.

\section{A. Determining the Order of the Reduced-order Models}

The first step in model-order reduction is to identify fast and slow states in the inverter dynamical model while acknowledging that the inverter could be interconnected to a network with dominantly inductive or resistive lines. To aid this, in Fig. 4 we plot eigenvalues and participation factors corresponding to a linearized version of the inverter dynamical model for parameters presented in Table $\mathrm{I}$ and inputs: $S^{\star}=[2,2]^{\top} \mathrm{pu}$, $V_{D Q}=[1,0]^{\top} \mathrm{pu}$. Two sets of results are plotted for inductive and resistive interconnecting lines, and they are distinguished based on the values of $R_{\mathrm{g}}$ and $L_{\mathrm{g}}$ utilized in the simulation. For the case with inductive (resistive) lines, we set $L_{\mathrm{g}}\left(R_{\mathrm{g}}\right)$ equal to the sum of the grid-side inductance (resistance) and the line inductance (resistance).

A careful examination of Fig. 4 reveals that a bandwidth of (approximately) $260 \mathrm{rad} \mathrm{s}^{-1}$ is a reasonable cut-off to separate slow and fast states for both inductive and resistive interconnections. The region shaded in gray in Fig. 4 identifies eigenvalues whose real parts take values less than $-260 \mathrm{rads}^{-1}$, and should be considered as fast dynamics. The choice of the cut-off bandwidth is determined based on the locus of (the real-part of) eigenvalues most influenced by fast states that are not as strongly dependent on the nature of interconnecting lines. A careful examination of Fig. 4 suggests that in this case, these fast states are $\Gamma_{d q}$, i.e., the states associated with the current controller ${ }^{3}$ The inferences reported above hold for a wide range of inputs $\left(S^{\star}, V_{D Q}\right)$ and line parameters $\left(R_{\mathrm{g}}, L_{\mathrm{g}}\right)$.

${ }^{3}$ The real-part of eigenvalues most impacted by $\Gamma_{d q}$, emphasized in Fig. 4 d), is $-266.7 \mathrm{rad} \mathrm{s}^{-1}$ for both cases considered. We establish the cut-off frequency to be $260 \mathrm{rad} \mathrm{s}^{-1}$ to go with a well-rounded number. 


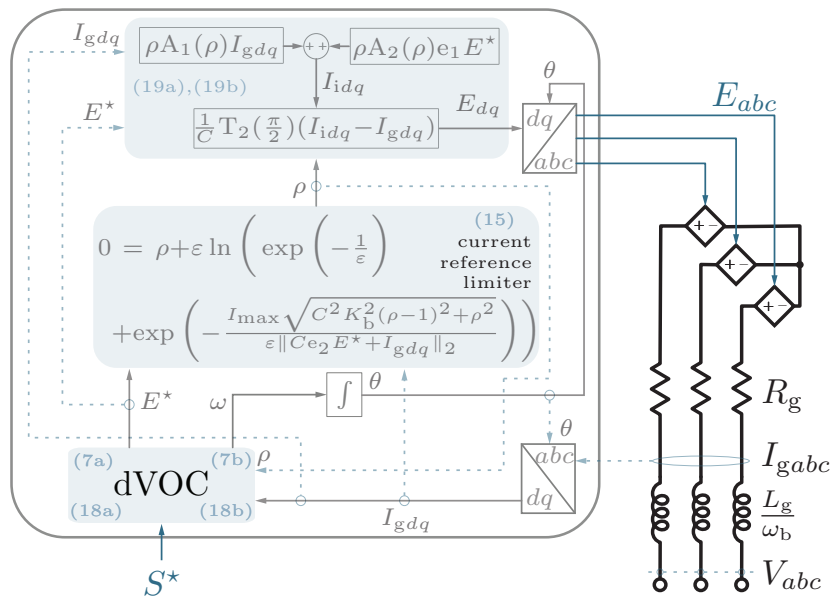

(a) Inductive interconnecting lines.

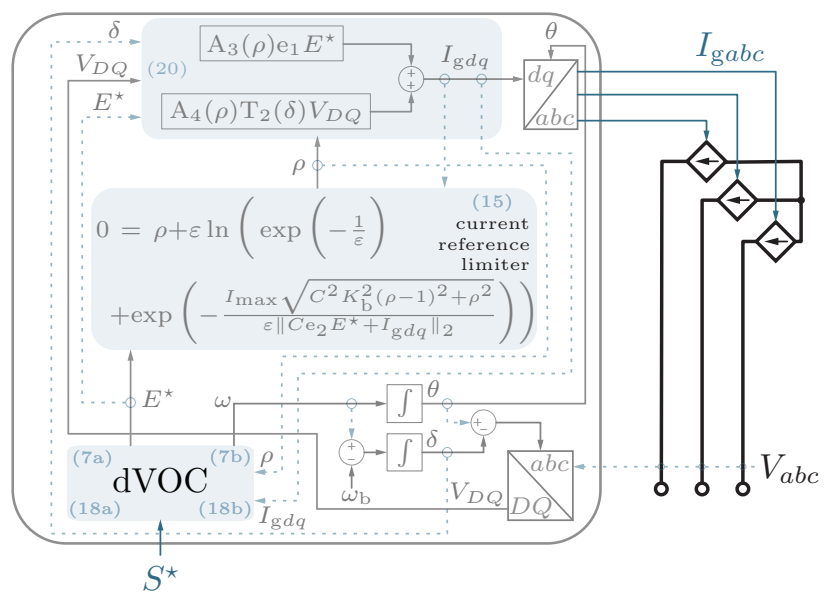

(b) Resistive interconnecting lines.

Fig. 3: Reduced-order models for GFM inverters with a current-reference limiter and dVOC.

Participation Factor (GFM inverter with inductive interconnecting lines)

\begin{tabular}{|lllllllllll|}
\hline & 0.1 & 0.2 & 0.3 & 0.4 & 0.5 & 0.6 & 0.7 & 0.8 & 0.9 & 1 \\
\hline & | & & &
\end{tabular}

Participation Factor (GFM inverter with resistive interconnecting lines) $\begin{array}{lllllllllll}0 & 0.1 & 0.2 & 0.3 & 0.4 & 0.5 & 0.6 & 0.7 & 0.8 & 0.9 & 1\end{array}$
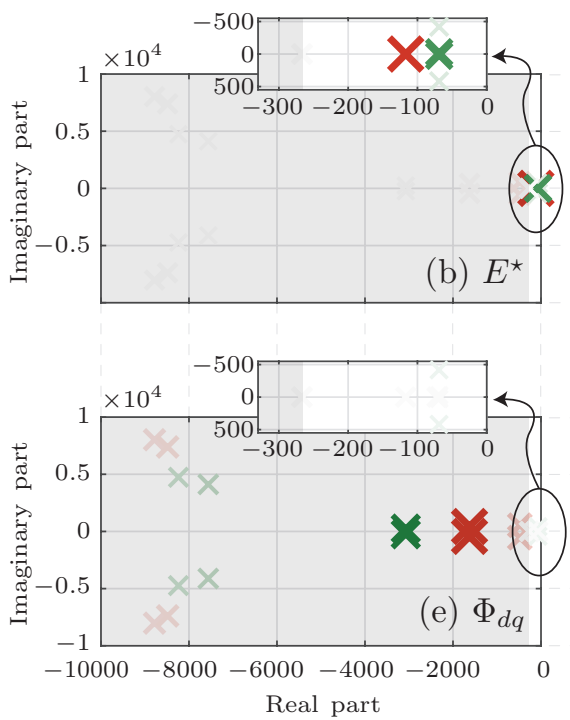
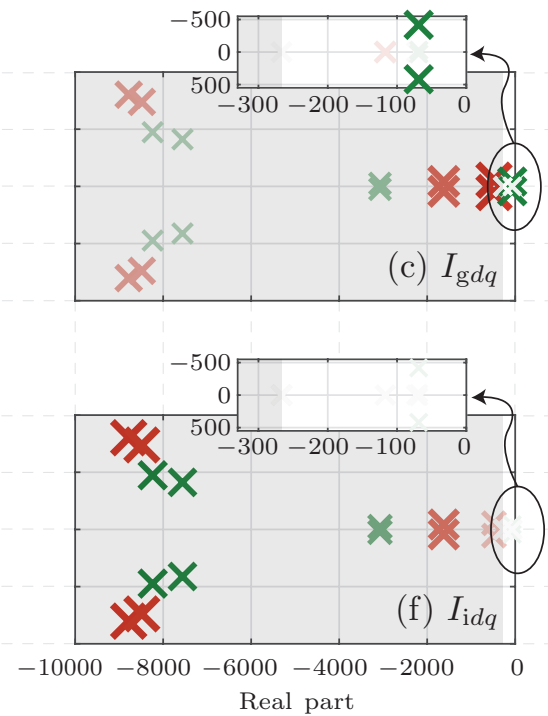
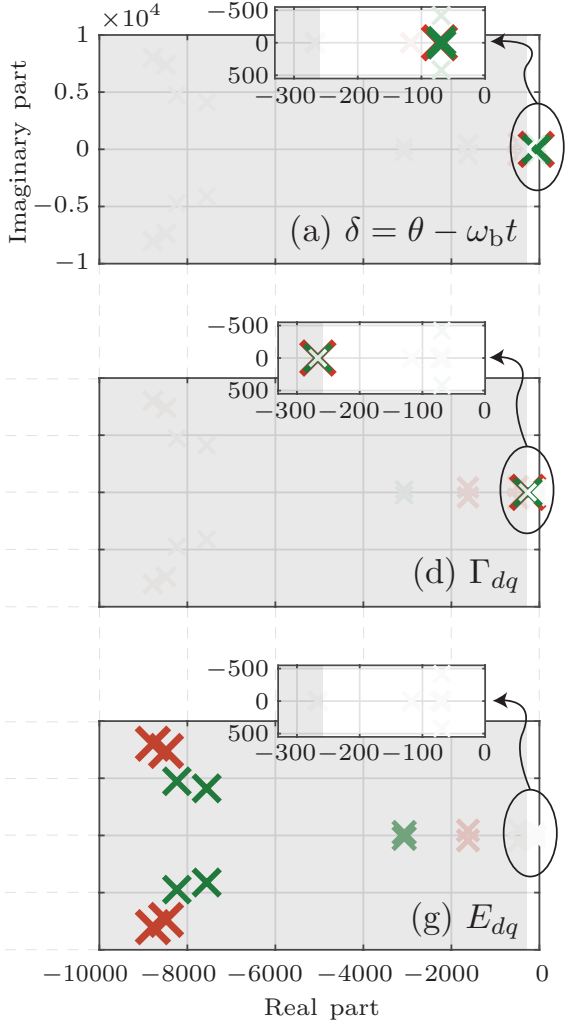

Fig. 4: Eigenvalues of the averaged full-order model's Jacobian matrix, with each eigenvalue color coded according to the participation factor of: (a) $\delta=\theta-\omega_{\mathrm{b}} t$, (b) $E^{\star}$, (c) $I_{\mathrm{g} d q}$, (d) $\Gamma_{d q}$ (e) $\Phi_{d q}$, (f) $I_{\mathrm{i} d q}$, and (g) $E_{d q}$. Elements of each $d q$ variable have identical participation factors. The case of inductive (resistive) interconnecting lines is colored green (red). The region shaded in gray identifies eigenvalues associated with fast states.

\section{B. Procedure Involved in Model-order Reduction}

The results presented in this subsection are based on singular perturbation analysis [27]. We require the following reasonable assumption for the results to hold:

Assumption 1. The GFM inverter's angular frequency, $\omega$, satisfies the constraint

$$
\left|\frac{\omega-\omega_{\mathrm{b}}}{\omega_{\mathrm{b}}}\right| \leq \epsilon
$$

where $\epsilon$ is a dimensionless parameter.

For a nominal frequency, $\omega_{\mathrm{b}}=60 \mathrm{~Hz}$, and with the choice $\epsilon=$ $260^{-1}$ (motivated by the discussion on cut-off bandwidth in Section IV-A, the above assumption implies that the reducedorder models that follow are valid when the GFM inverter's frequency is within $59.77 \mathrm{~Hz}$ and $60.23 \mathrm{~Hz}$.

The following steps, which are described in detail in the Appendix, are involved in model reduction:

1. The dynamics introduced in Section IIII are represented 
compactly as a 12th-order set of differential equations by:

(i) substituting (12a) into (12b) and solving for $I_{\mathrm{i} d q}^{\star}$,

(ii) substituting the result into (11), (12a) and (13a) (equation (12b) is no longer needed),

(iii) substituting the new expression for (13a) into (13b),

(iv) using the new expression for (13b) to obtain an expression for $U_{d q}$ (recall that $U_{d q}=U_{d q}^{\star}$ ), and substituting this into (8a) (equation (13b) is no longer needed).

2. The right- and left-hand sides of the differential equations for fast states are multiplied by $\epsilon=260^{-1}$. Resulting equations are in the standard singular perturbation form:

$$
\begin{aligned}
\dot{x} & =f(x, z, \epsilon), \\
\epsilon \dot{z} & =g(x, z, \epsilon),
\end{aligned}
$$

where $f(\cdot, \cdot, \cdot)$ and $g(\cdot, \cdot, \cdot)$ are continuously differentiable functions of their arguments, the elements of $x$ are the slowvarying states, and the elements of $z$ are the fast-varying states. From the discussion in Section IV-A, we note that when inductive lines interconnect the GFM inverter to the bus, $x=\left[\theta, E^{\star}, I_{\mathrm{g} d q}^{\top}\right]^{\top}$ and $z=\left[I_{\mathrm{i} d q}^{\top}, E_{d q}^{\top}, \Phi_{d q}^{\top}, \Gamma_{d q}^{\top}\right]^{\top}$, and (14) is recovered by collecting the new expressions obtained for (8a), (8b), (12a), and (13a) and multiplying the left- and right-hand sides of each equation by $\epsilon$. On the otherhand, when resistive interconnecting lines are used, $x=\left[\theta, E^{\star}\right]^{\top}$ and $z=\left[I_{\mathrm{g} d q}^{\top}, I_{\mathrm{i} d q}^{\top}, E_{d q}^{\top}, \Phi_{d q}^{\top}, \Gamma_{d q}^{\top}\right]^{\top}$, and (14) is recovered by collecting the new expressions obtained for (8a), (8b), (8c), (12a), and (13a) and multiplying the leftand right-hand sides of each equation by $\epsilon$.

3. The set of differential equations comprising (14b) are replaced with algebraic counterparts. We employ a zeroorder approximation of the integral manifold for $z$ as the algebraic counterpart; this is derived by setting $\epsilon=0$ on the left-hand side of $14 \mathrm{~b}$, setting $\frac{\omega-\omega_{\mathrm{b}}}{\omega_{\mathrm{b}}}=0$ in the resulting set of equations (this follows from Assumption 1, and solving for $z$ as a function of $x$. The resulting set of equations yield a 4th- (2nd-) order model for GFM inverters with inductive (resistive) lines.

\section{Reduced-order Models}

Following the steps above, which are described in detail in the Appendix, it emerges that the action of the currentreference limiter is captured by solving for $\rho$ in

$$
\begin{aligned}
0 & =\rho+\varepsilon \ln \left(\exp \left(-\frac{1}{\varepsilon}\right)\right. \\
& \left.+\exp \left(-\frac{I_{\max } \sqrt{C^{2} K_{\mathrm{b}}^{2}(\rho-1)^{2}+\rho^{2}}}{\varepsilon\left\|C \mathrm{e}_{2} E^{\star}+I_{\mathrm{g} d q}\right\|_{2}}\right)\right) .
\end{aligned}
$$

Compared to [11, the above algebraic constraint is recognizably cumbersome; however, it captures the impact of currentreference limiting in an analytically tractable fashion.

We summarize the differential and algebraic equations corresponding to the two sets of reduced-order models next.
Before doing so, we will find the below definitions useful:

$$
\begin{aligned}
& \mathrm{A}_{1}(\rho)=\left[\begin{array}{cc}
\frac{\rho}{C^{2} K_{\mathrm{b}}^{2}(\rho-1)^{2}+\rho^{2}} & -\frac{C K_{\mathrm{b}}(\rho-1)}{C^{2} K_{\mathrm{b}}^{2}(\rho-1)^{2}+\rho^{2}} \\
\frac{C K_{\mathrm{b}}(\rho-1)}{C^{2} K_{\mathrm{b}}^{2}(\rho-1)^{2}+\rho^{2}} & \frac{\rho}{C^{2} K_{\mathrm{b}}^{2}(\rho-1)^{2}+\rho^{2}}
\end{array}\right], \\
& \mathrm{A}_{2}(\rho)=\left[\begin{array}{cc}
-\frac{C^{2} K_{\mathrm{b}}(\rho-1)}{C^{2} K_{\mathrm{b}}^{2}(\rho-1)^{2}+\rho^{2}} & -\frac{C \rho}{C^{2} K_{\mathrm{b}}^{2}(\rho-1)^{2}+\rho^{2}} \\
\frac{C \rho}{C^{2} K_{\mathrm{b}}^{2}(\rho-1)^{2}+\rho^{2}} & -\frac{C^{2} K_{\mathrm{b}}(\rho-1)}{C^{2} K_{\mathrm{b}}^{2}(\rho-1)^{2}+\rho^{2}}
\end{array}\right], \\
& \mathrm{A}_{3}(\rho)=\left[\begin{array}{cc}
\frac{f_{1}(\rho)}{f_{5}(\rho)} & -\frac{f_{2}(\rho)}{f_{5}(\rho)} \\
\frac{f_{2}(\rho)}{f_{5}(\rho)} & \frac{f_{1}(\rho)}{f_{5}(\rho)}
\end{array}\right], \quad \mathrm{A}_{4}(\rho)=\left[\begin{array}{cc}
\frac{f_{3}(\rho)}{f_{5}(\rho)} & -\frac{f_{4}(\rho)}{f_{5}(\rho)} \\
\frac{f_{4}(\rho)}{f_{5}(\rho)} & \frac{f_{3}(\rho)}{f_{5}(\rho)}
\end{array}\right]
\end{aligned}
$$

where, we introduce:

$$
\begin{aligned}
f_{1}(\rho) & =\left(C L_{\mathrm{g}}-1\right) K_{\mathrm{b}} \rho(\rho-1)+R_{\mathrm{g}} \rho^{2}, \\
f_{2}(\rho) & =C R_{\mathrm{g}} K_{\mathrm{b}} \rho(\rho-1)-L_{\mathrm{g}} \rho^{2}, \\
f_{3}(\rho) & =K_{\mathrm{b}} \rho(\rho-1)-R_{\mathrm{g}}\left(C^{2} K_{\mathrm{b}}^{2}(\rho-1)^{2}+\rho^{2}\right), \\
f_{4}(\rho) & =L_{\mathrm{g}} \rho^{2}+C K_{\mathrm{b}}^{2}(\rho-1)^{2}\left(C L_{\mathrm{g}}-1\right), \\
f_{5}(\rho) & =\left(C L_{\mathrm{g}}-1\right)^{2} K_{\mathrm{b}}^{2}(\rho-1)^{2}+\left(C R_{\mathrm{g}}\right)^{2} K_{\mathrm{b}}^{2}(\rho-1)^{2} \\
& -2 K_{\mathrm{b}} R_{\mathrm{g}} \rho(\rho-1)+\rho^{2}\left(R_{\mathrm{g}}^{2}+L_{\mathrm{g}}^{2}\right) .
\end{aligned}
$$

1) Inductive Interconnecting Lines: The dynamics of the slow-varying states are given by

$$
\begin{aligned}
\dot{\theta} & =\omega_{\mathrm{b}}+\frac{\omega_{\mathrm{b}} \kappa_{1}}{\left(E^{\star}\right)^{2}} \mathrm{e}_{1}^{\top} \mathrm{T}_{2}\left(\psi-\frac{\pi}{2}\right)\left(S^{\star}-S\right) \\
\dot{E}^{\star} & =\frac{\omega_{\mathrm{b}} \kappa_{1}}{E^{\star}} \mathrm{e}_{2}^{\top} \mathrm{T}_{2}\left(\psi-\frac{\pi}{2}\right)\left(S^{\star}-S\right) \\
& +\omega_{\mathrm{b}} \kappa_{2}\left(E_{\mathrm{b}}^{2}-\left(E^{\star}\right)^{2}\right) E^{\star} \\
\dot{I}_{\mathrm{g} d q} & =\omega_{\mathrm{b}}\left(\mathrm{T}_{2}\left(\frac{\pi}{2}\right)\left(\mathrm{I}-\frac{1}{L_{\mathrm{g}} C}\left(\mathrm{I}-\rho \mathrm{A}_{1}(\rho)\right)\right)-\frac{R_{\mathrm{g}}}{L_{\mathrm{g}}} \mathrm{I}\right) I_{\mathrm{g} d q} \\
& +\frac{\omega_{\mathrm{b}}}{L_{\mathrm{g}}}\left(\frac{\rho}{C} \mathrm{~T}_{2}\left(\frac{\pi}{2}\right) \mathrm{A}_{2}(\rho) \mathrm{e}_{1} E^{\star}-\mathrm{T}_{2}(\delta) V_{D Q}\right)
\end{aligned}
$$

where $\rho$ is given by the solution of $(15)$ and the active- and reactive-power values, $P, Q$ in $S=[P, Q]^{\top}$ take the form:

$$
\begin{aligned}
P= & I_{\mathrm{g} d q}^{\top}\left(\frac{\rho}{C} \mathrm{~A}_{1}(\rho)^{\top} \mathrm{T}_{2}\left(\frac{\pi}{2}\right)^{\top}-\frac{1}{C} \mathrm{~T}_{2}\left(\frac{\pi}{2}\right)^{\top}\right) I_{\mathrm{g} d q} \\
& +\frac{\rho}{C} \mathrm{e}_{1}^{\top} \mathrm{A}_{2}(\rho)^{\top} \mathrm{T}_{2}\left(\frac{\pi}{2}\right)^{\top} E^{\star} I_{\mathrm{g} d q}, \\
Q= & I_{\mathrm{g} d q}^{\top}\left(\frac{1}{C} \mathrm{I}-\frac{\rho}{C} \mathrm{~A}_{1}(\rho)^{\top}\right) I_{\mathrm{g} d q} \\
& -\frac{\rho}{C} \mathrm{e}_{1}^{\top} \mathrm{A}_{2}(\rho)^{\top} E^{\star} I_{\mathrm{g} d q} .
\end{aligned}
$$

Algebraic equations for the fast-varying state variables are:

$$
\begin{aligned}
I_{\mathrm{i} d q} & =\rho\left(\mathrm{A}_{1}(\rho) I_{\mathrm{g} d q}+\mathrm{A}_{2}(\rho) \mathrm{e}_{1} E^{\star}\right), \\
E_{d q} & =\frac{1}{C} \mathrm{~T}_{2}\left(\frac{\pi}{2}\right)\left(I_{\mathrm{i} d q}-I_{\mathrm{g} d q}\right), \\
\Phi_{d q} & =\frac{1}{\rho K_{\mathrm{I} v}}(\rho-1)\left(K_{\mathrm{b}} K_{\mathrm{P} v}-1\right) I_{\mathrm{i} d q}, \\
\Gamma_{d q} & =\frac{R_{\mathrm{i}}}{K_{\mathrm{I} i}} I_{\mathrm{i} d q} .
\end{aligned}
$$

Note that the equations comprising (19) can be expressed as functions of $\delta, E^{\star}, I_{\mathrm{g} d q}$, and $\rho$. 
2) Resistive Interconnecting Lines: The dynamics of $\theta, E^{\star}$ are the same as in 17a - $17 \mathrm{~b} ; P, Q$ in $S=[P, Q]^{\top}$ remain defined as in (18a)-(18b); and $\rho$ is still defined by the solution of (15). However, $I_{\mathrm{g} d q}$, which is now a fast-varying state, is defined algebraically via

$$
I_{\mathrm{g} d q}=\mathrm{A}_{3}(\rho) \mathrm{e}_{1} E^{\star}+\mathrm{A}_{4}(\rho) \mathrm{T}_{2}(\delta) V_{D Q} .
$$

The algebraic equations for the other fast-varying state variables are the same as $19 \mathrm{a}-19 \mathrm{~d}$.

Remark 2 (Structure of Reduced-order Models). The reducedorder models for the slow-varying states in both cases considered above are self contained, in that they do not invoke any fast-varying states. The dynamics are DAE models in each case, with the algebraic component given by (15).

\section{Special Case with Current-reference Limiter Ignored}

The current-reference limiter can be ignored in the dynamical model presented in Section IV-B by setting $\rho=1$. The collection of slow and fast states for the inductive and resistive interconnecting lines remains the same as before.

For inductive interconnecting lines, the dynamics of $\theta$ and $E^{\star}$ are the same as $\left.7 \mathrm{a}\right)-(7 \mathrm{~b})$, except, with the active- and reactive-power values, $P, Q$ simplifying to: $P=\mathrm{e}_{1}^{\top} E^{\star} I_{\mathrm{g} d q}$, $Q=-\mathrm{e}_{2}^{\top} E^{\star} I_{\mathrm{g} d q}$. The dynamics of $I_{\mathrm{g} d q}$ are given by

$\dot{I}_{\mathrm{g} d q}=\omega_{\mathrm{b}}\left(\mathrm{T}_{2}\left(\frac{\pi}{2}\right)-\frac{R_{\mathrm{g}}}{L_{\mathrm{g}}} \mathrm{I}\right) I_{\mathrm{g} d q}+\frac{\omega_{\mathrm{b}}}{L_{\mathrm{g}}}\left(\mathrm{e}_{1} E^{\star}-\mathrm{T}_{2}(\delta) V_{D Q}\right)$.

The algebraic equations for the fast-varying state variables are:

$$
\begin{aligned}
& I_{\mathrm{i} d q}=C \mathrm{e}_{2} E^{\star}+I_{\mathrm{g} d q}, \quad E_{d q}=\mathrm{e}_{1} E^{\star}, \\
& \Phi_{d q}=[0,0]^{\top}, \quad \Gamma_{d q}=\frac{R_{\mathrm{i}}}{K_{\mathrm{I} i}}\left(C \mathrm{e}_{2} E^{\star}+I_{\mathrm{g} d q}\right) .
\end{aligned}
$$

From above, we see that the filter-capacitor voltage, $E_{d q}$, is regulated to the reference generated by the AHO model, $\mathrm{e}_{1} E^{\star}$.

For resistive interconnecting lines, the dynamics of $\theta, E^{\star}$ are the same as reported above for inductive interconnecting lines, as are algebraic constraints for $I_{\mathrm{i} d q}, E_{d q}, \Phi_{d q}, \Gamma_{d q}$. The algebraic constraint for $I_{\mathrm{g} d q}$ can be recovered from 20 by substituting $\mathrm{A}_{3}(1)$ and $\mathrm{A}_{4}(1)$.

\section{Numerical Results}

We consider a GFM inverter with dVOC interconnected to an infinite bus via: i) an inductive line, and ii) a resistive line. The active- and reactive-power references, and infinitebus voltage are varied over a $10 \mathrm{~s}$ time interval according to Fig. 5. We include simulations from a switched version of the model in Fig. 11, the averaged full-order model discussed in Section III] and the reduced-order models discussed in Section IV-B, Parameters in Table Iare used in all simulations.

The computational effort required by the switched full-order model, the averaged full-order model, and the reduced-order model are $40.5 \mathrm{~s}, 14.3 \mathrm{~s}$, and $1.9 \mathrm{~s}$, respectively. Figure 6 shows the root mean square error (RMSE) of the averaged full-order model's response and the reduced-order model's response, relative to the switched full-order model. Additionally, Figs.7a
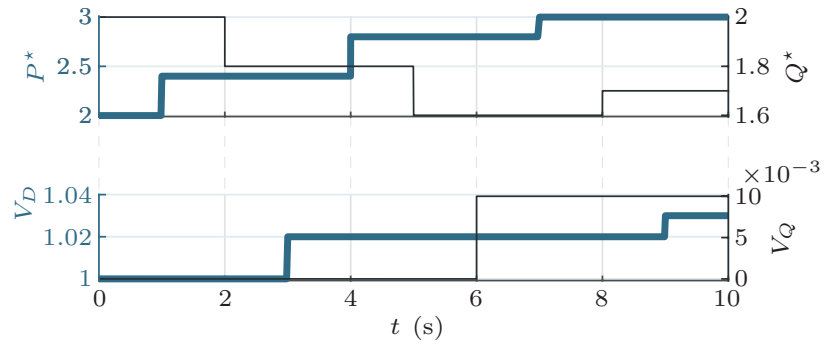

Fig. 5: Profile of power-reference inputs and $D Q$ components of the grid-side voltage utilized in the simulations.

and $7 \mathrm{~b}$ depict the output voltage and current of the switched model, the averaged full-order model, and the reduced model. Note that the reduced-order models capture the effects of the current-reference limiter. Understandably, the reduced-order models do not capture all higher-order transients, but they do preserve all dominant transient behavior and return the same steady-state values as the higher-order models. The numerical results show that, although the RMSE associated with the reduced-order models and the full-order model have identical orders of magnitude, our proposed reduced-order models require an order-of-magnitude less computational effort.

\section{Vi. Concluding Remarks \& Future Work}

This work outlined reduced-order models for grid-forming inverters realized with dispatchable Virtual Oscillator Control. Compared to previous efforts for model reduction, our proposed models retain the effects of the current-reference limiter in the model response. Simulation results indicate that the proposed reduced-order models require an order-of-magnitude less computational effort to produce results with the same order-of-magnitude accuracy as the averaged full-order model. Future work includes extending the results presented in this paper to other types of GFM inverters.

\section{REFERENCES}

[1] J. A. Taylor, S. V. Dhople, and D. S. Callaway, "Power systems without fuel," Renewable and Sustainable Energy Reviews, vol. 57, pp. 1322 1336, May 2016.

[2] F. Milano, F. Dörfler, G. Hug, D. J. Hill, and G. Verbič, "Foundations and challenges of low-inertia systems (invited paper)," in IEEE Power Systems Computation Conference, Jun. 2018, pp. 1-25.

[3] M. C. Chandorkar, D. M. Divan, and R. Adapa, "Control of parallel connected inverters in standalone AC supply systems," IEEE Trans. Ind. Appl., vol. 29, no. 1, pp. 136-143, Jan. 1993.

[4] N. Pogaku, M. Prodanovic, and T. C. Green, "Modeling, analysis and testing of autonomous operation of an inverter-based microgrid," IEEE Trans. Power Electron., vol. 22, no. 2, pp. 613-625, Mar. 2007.

[5] Q.-C. Zhong, "Robust droop controller for accurate proportional load sharing among inverters operated in parallel," IEEE Trans. Ind. Electron., vol. 60, no. 4, pp. 1281-1290, Apr. 2013.

[6] J. Driesen and K. Visscher, "Virtual synchronous generators," in 2008 IEEE Power and Energy Society General Meeting, Conversion and Delivery of Electrical Energy in the 21st Century, Jul. 2008, pp. 1-3.

[7] Q.-C. Zhong and G. Weiss, "Synchronverters: Inverters that mimic synchronous generators," IEEE Trans. Ind. Electron., vol. 58, no. 4, pp. 1259-1267, Apr. 2011.

[8] T. Shintai, Y. Miura, and T. Ise, "Oscillation damping of a distributed generator using a virtual synchronous generator," IEEE Trans. Power Del., vol. 29, no. 2, pp. 668-676, Apr. 2014.

[9] S. D’Arco, J. Suul, and O. Fosso, "A virtual synchronous machine implementation for distributed control of power converters in smartgrids," Electric Power Systems Research, vol. 122, pp. 180 - 197, 2015. 


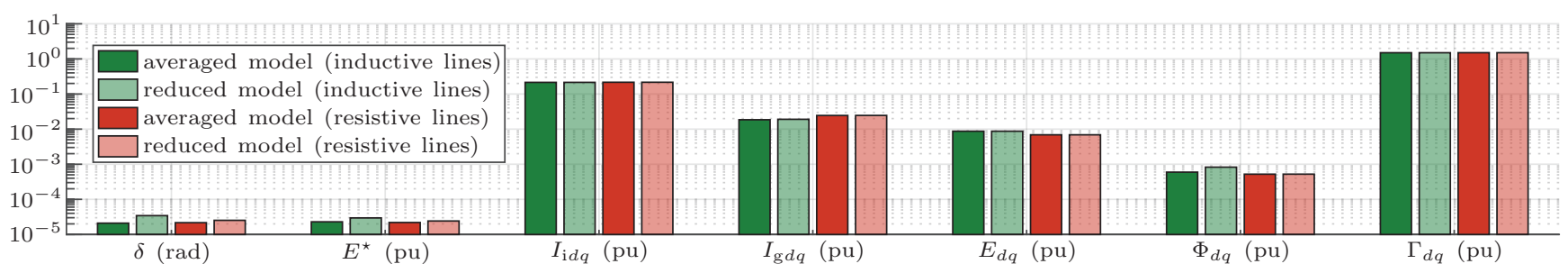

Fig. 6: RMSE of the averaged full-order model and the reduced-order model relative to the switched model.
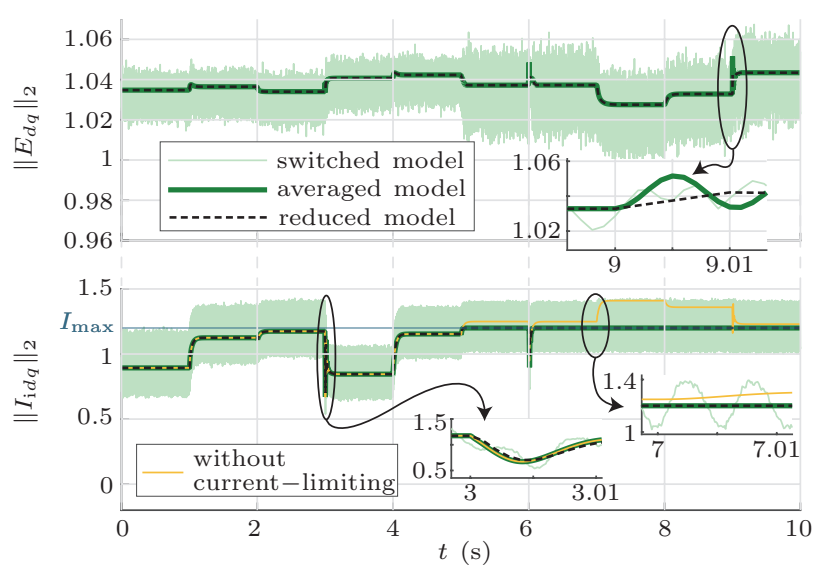

(a) With inductive interconnecting lines.
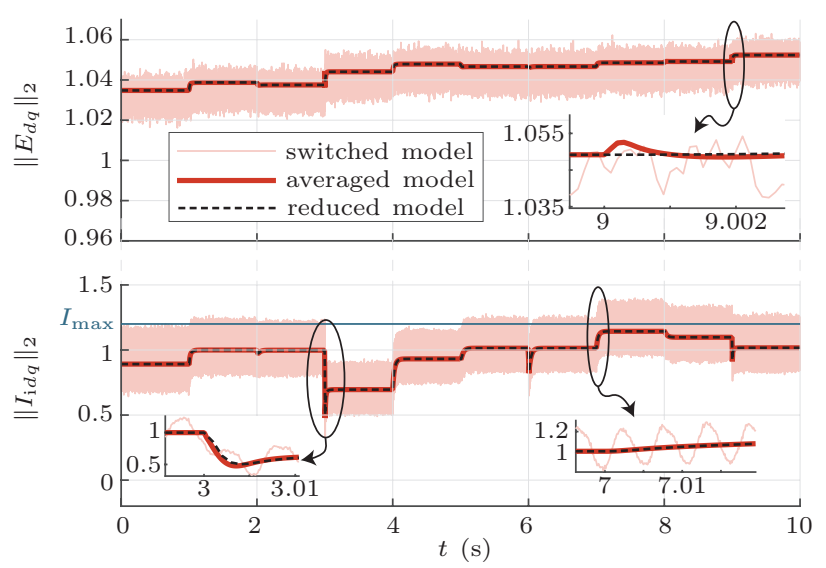

(b) With resistive interconnecting lines.

Fig. 7: Output response of the GFM inverter's switched model, averaged full-order model, and reduced-order model.

[10] J. Liu, Y. Miura, H. Bevrani, and T. Ise, "Enhanced virtual synchronous generator control for parallel inverters in microgrids," IEEE Trans. Smart Grid, vol. 8, no. 5, pp. 2268-2277, Sep. 2017.

[11] J. Aracil and F. Gordillo, "On the control of oscillations in dc-ac converters," in IEEE Annual Conference of the Industrial Electronics Society, vol. 4, 2002, pp. 2820-2825.

[12] B. B. Johnson, S. V. Dhople, A. O. Hamadeh, and P. T. Krein, "Synchronization of Nonlinear Oscillators in an LTI Electrical Power Network," IEEE Trans. Circuits Syst. I, Reg. Papers, vol. 61, no. 3, pp. 834-844, Mar. 2014.

[13] L. A. Tôrres, J. P. Hespanha, and J. Moehlis, "Synchronization of Identical Oscillators Coupled Through a Symmetric Network With Dynamics: A Constructive Approach With Applications to Parallel Operation of Inverters," IEEE Trans. Autom. Control, vol. 60, no. 12, pp. 3226-3241, Dec. 2015.

[14] M. Li, Y. Gui, Y. Guan, J. Matas, J. M. Guerrero, and J. C. Vasquez, "Inverter parallelization for an islanded microgrid using the Hopf oscillator controller approach with self-synchronization capabilities," IEEE Trans. Ind. Electron., pp. 1-1, 2020.

[15] D. Raisz, T. T. Thai, and A. Monti, "Power control of virtual oscillator controlled inverters in grid-connected mode," IEEE Trans. Power Electron., vol. 34, no. 6, pp. 5916-5926, Jun. 2019.

[16] M. Lu, S. Dutta, V. Purba, S. Dhople, and B. Johnson, "A gridcompatible virtual oscillator controller: Analysis and design," in IEEE Energy Conversion Congress and Exposition, 2019, pp. 2643-2649.

[17] H. Yu, M. A. Awal, H. Tu, I. Husain, and S. Lukic, "Comparative transient stability assessment of droop and dispatchable virtual oscillator controlled grid-connected inverters," IEEE Trans. Power Electron., vol. 36, no. 2, pp. 2119-2130, 2021.

[18] D. Groß, M. Colombino, J. Brouillon, and F. Dörfler, "The effect of transmission-line dynamics on grid-forming dispatchable virtual oscillator control," IEEE Trans. Control of Network Systems, vol. 6, no. 3, pp. 1148-1160, Sep. 2019.

[19] A. Tayyebi, D. Groß, A. Anta, F. Kupzog, and F. Dörfler, "Frequency stability of synchronous machines and grid-forming power converters," IEEE Journal of Emerging and Selected Topics in Power Electronics, vol. 8, no. 2, pp. 1004-1018, 2020.

[20] M. A. Awal and I. Husain, "Unified virtual oscillator control for gridforming and grid-following converters," IEEE Journal of Emerging and Selected Topics in Power Electronics, To Appear, 2020.

[21] J. Li, J. E. Fletcher, D. G. Holmes, and B. P. McGrath, "Developing a machine equivalent inertial response for a virtual oscillator controlled inverter in a machine-inverter based microgrid," in Proc. of the IEEE Energy Conversion Congress and Exposition, 2020, pp. 4314-4321.

[22] T. Heins, T. Tran, D. Raisz, and A. Monti, "Power Control of AndronovHopf Oscillator Based Distributed Generation in Grid-Connected Microgrids," in Advances in Engineering Research and Application, K.-U. Sattler, D. C. Nguyen, N. P. Vu, B. T. Long, and H. Puta, Eds. Cham: Springer International Publishing, 2021, pp. 675-687.

[23] G. Seo, M. Colombino, I. Subotic, B. Johnson, D. Groß, and F. Dörfler, "Dispatchable virtual oscillator control for decentralized inverterdominated power systems: Analysis and experiments," in IEEE Applied Power Electronics Conference and Exposition, 2019, pp. 561-566.

[24] M. Colombino, D. Groß, J. Brouillon, and F. Dörfler, "Global phase and magnitude synchronization of coupled oscillators with application to the control of grid-forming power inverters," IEEE Trans. Autom. Control, vol. 64, no. 11, pp. 4496-4511, Nov. 2019.

[25] M. Lu, V. Purba, S. Dhople, and B. Johnson, "Comparison of Droop Control and Virtual Oscillator Control Realized by Andronov-Hopf Dynamics," in Proc. of the IEEE Industrial Electronics Society, 2020, pp. 4051-4056.

[26] M. Sinha, F. Dörfler, B. B. Johnson, and S. V. Dhople, "Virtual oscillator control subsumes droop control," in Proc. of the 2015 American Control Conference (ACC), 2015, pp. 2353-2358.

[27] P. Kokotović, H. K. Khalil, and J. O'Reilly, Singular Perturbation Methods in Control: Analysis and Design, ser. Classics in Applied Mathematics. Society for Industrial and Applied Mathematics, 1986.

[28] N. Bottrell and T. C. Green, "Comparison of current-limiting strategies during fault ride-through of inverters to prevent latch-up and wind-up," IEEE Trans. Power Electron., vol. 29, no. 7, pp. 3786-3797, 2014.

[29] I. Sadeghkhani, M. E. Hamedani Golshan, J. M. Guerrero, and A. Mehrizi-Sani, "A current limiting strategy to improve fault ridethrough of inverter interfaced autonomous microgrids," IEEE Trans. Smart Grid, vol. 8, no. 5, pp. 2138-2148, 2017.

[30] T. Qoria, F. Gruson, F. Colas, X. Kestelyn, and X. Guillaud, "Current limiting algorithms and transient stability analysis of grid-forming VSCs," Electric Power Systems Research, vol. 189, pp. 1-8, 2020.

[31] L. Luo and S. V. Dhople, "Spatiotemporal model reduction of inverterbased islanded microgrids," IEEE Trans. Energy Convers., vol. 29, no. 4, pp. 823-832, Dec. 2014.

[32] P. Vorobev, P. Huang, M. A. Hosani, J. Kirtley, and K. Turitsyn, "Highfidelity model order reduction for microgrids stability assessment," IEEE Trans. Power Syst., vol. 33, no. 1, pp. 874-887, Jan 2018. 
[33] O. O. Ajala, A. D. Domínguez-García, and P. W. Sauer, A Hierarchy of Models for Inverter-Based Microgrids. Springer-Verlag, Berlin, 2017.

[34] M. Rasheduzzaman, J. A. Mueller, and J. W. Kimball, "Reduced-order small-signal model of microgrid systems," IEEE Trans. Sustain. Energy, vol. 6, no. 4, pp. 1292-1305, 2015.

[35] I. Caduff, U. Markovic, C. Roberts, G. Hug, and E. Vrettos, "Reducedorder modeling of inverter-based generation using hybrid singular perturbation," Electric Power Systems Research, vol. 190, p. 106773, 2021.

[36] W. Hu, Z. Wu, and V. Dinavahi, "Dynamic analysis and model order reduction of virtual synchronous machine based microgrid," IEEE Access, vol. 8, pp. 106585-106600, 2020.

[37] M. M. S. Khan, Y. Lin, B. Johnson, V. Purba, M. Sinha, and S. Dhople, "A reduced-order aggregated model for parallel inverter systems with virtual oscillator control," in Proc. of the IEEE Workshop on Control and Modeling for Power Electronics, 2018, pp. 1-6.

[38] I. J. Perez-arriaga, G. C. Verghese, and F. C. Schweppe, "Selective modal analysis with applications to electric power systems, part i: Heuristic introduction," IEEE Trans. Power Apparatus and Systems, vol. PAS-101, no. 9, pp. 3117-3125, 1982.

[39] A. Bergen and V. Vittal, Power Systems Analysis. Prentice Hall, 2000.

[40] A. Reznik, M. G. Simões, A. Al-Durra, and S. M. Muyeen, "LCL filter design and performance analysis for grid-interconnected systems," IEEE Trans. Ind. Appl., vol. 50, no. 2, pp. 1225-1232, 2014.

[41] P. Channegowda and V. John, "Filter optimization for grid interactive voltage source inverters," IEEE Trans. Ind. Electron., vol. 57, no. 12, pp. 4106-4114, 2010.

[42] M. G. Taul, X. Wang, P. Davari, and F. Blaabjerg, "Current limiting control with enhanced dynamics of grid-forming converters during fault conditions," IEEE Journal of Emerging and Selected Topics in Power Electronics, vol. 8, no. 2, pp. 1062-1073, 2020.

[43] A. Yazdani and R. Iravani, Voltage-Sourced Converters in Power Systems. Wiley, Jan. 2010.

\section{APPENDIX \\ MODEL-ORDER REDUCTION STEPS}

\section{A. The 12th-order Model}

Following step 1 of Section IV-B, the dynamics introduced in Section III can be expressed compactly as follows:

$$
\begin{aligned}
\dot{\delta} & =\frac{\omega_{\mathrm{b}} \kappa_{1}}{\left(E^{\star}\right)^{2}} \mathrm{e}_{1}^{\top} \mathrm{T}_{2}\left(\psi-\frac{\pi}{2}\right)\left(S^{\star}-S\right), \\
\dot{E}^{\star}= & \frac{\omega_{\mathrm{b}} \kappa_{1}}{E^{\star}} \mathrm{e}_{2}^{\top} \mathrm{T}_{2}\left(\psi-\frac{\pi}{2}\right)\left(S^{\star}-S\right) \\
& \quad+\omega_{\mathrm{b}} \kappa_{2}\left(E_{\mathrm{b}}^{2}-\left(E^{\star}\right)^{2}\right) E^{\star} \\
\dot{I}_{\mathrm{g} d q} & =\left(\omega \mathrm{T}_{2}\left(\frac{\pi}{2}\right)-\omega_{\mathrm{b}} \frac{R_{\mathrm{g}}}{L_{\mathrm{g}}} \mathrm{I}\right) I_{\mathrm{g} d q}+\frac{\omega_{\mathrm{b}}}{L_{\mathrm{g}}}\left(E_{d q}-\mathrm{T}_{2}(\delta) V_{D Q}\right), \\
\dot{I}_{\mathrm{i} d q} & =-\frac{\omega_{\mathrm{b}}\left(R_{\mathrm{i}}+K_{\mathrm{P} i}\right)}{L_{\mathrm{i}}} I_{\mathrm{i} d q}+\frac{\omega_{\mathrm{b}}}{L_{\mathrm{i}}}\left(K _ { \mathrm { P } i } \left(\rho \left(K_{\mathrm{P} v} \mathrm{e}_{1} E^{\star}\right.\right.\right. \\
& \left.\left.+I_{\mathrm{g} d q}+K_{\mathrm{I} v} \Phi_{d q}-\left(K_{\mathrm{P} v} \mathrm{I}+\frac{\omega}{\omega_{\mathrm{b}}} C \mathrm{~T}_{2}\left(\frac{\pi}{2}\right)\right) E_{d q}\right)\right) \\
+ & \left.K_{\mathrm{I} i} \Gamma_{d q}\right), \\
\dot{E}_{d q} & =\omega \mathrm{T}_{2}\left(\frac{\pi}{2}\right) E_{d q}+\frac{\omega_{\mathrm{b}}}{C}\left(I_{\mathrm{i} d q}-I_{\mathrm{g} d q}\right) \\
\dot{\Phi}_{d q} & =\omega_{\mathrm{b}}\left(1+K_{\mathrm{b}}(\rho-1) K_{\mathrm{P} v}\right) \mathrm{e}_{1} E^{\star} \\
- & \omega_{\mathrm{b}}\left(\mathrm{I}+K_{\mathrm{b}}(\rho-1)\left(K_{\mathrm{P} v} \mathrm{I}+\frac{\omega}{\omega_{\mathrm{b}}} C \mathrm{~T}_{2}\left(\frac{\pi}{2}\right)\right)\right) E_{d q} \\
+ & \omega_{\mathrm{b}} K_{\mathrm{b}}(\rho-1)\left(K_{\mathrm{I} v} \Phi_{d q}+I_{\mathrm{g} d q}\right), \\
\dot{\Gamma}_{d q} & =\omega_{\mathrm{b}} \rho\left(K_{\mathrm{P} v} \mathrm{e}_{1} E^{\star}+K_{\mathrm{I} v} \Phi_{d q}+I_{\mathrm{g} d q}\right. \\
& \left.-\left(K_{\mathrm{P} v} \mathrm{I}+\frac{\omega}{\omega_{\mathrm{b}}} C \mathrm{~T}_{2}\left(\frac{\pi}{2}\right)\right) E_{d q}\right)-\omega_{\mathrm{b}} I_{\mathrm{i} d q}, \\
\rho & =-\varepsilon \ln \left(\exp \left(\frac{-1}{\varepsilon}\right)+\exp \left(-I_{\mathrm{max}} \div \varepsilon \| K_{\mathrm{P} v} \mathrm{e}_{1} E^{\star}\right.\right.
\end{aligned}
$$

$$
\begin{gathered}
\dot{\delta}=\frac{\omega_{\mathrm{b}} \kappa_{1}}{\left(E^{\star}\right)^{2}} \mathrm{e}_{1}^{\top} \mathrm{T}_{2}\left(\psi-\frac{\pi}{2}\right)\left(S^{\star}-S\right), \\
\dot{E}^{\star}=\frac{\omega_{\mathrm{b}} \kappa_{1}}{E^{\star}} \mathrm{e}_{2}^{\top} \mathrm{T}_{2}\left(\psi-\frac{\pi}{2}\right)\left(S^{\star}-S\right) \\
+\omega_{\mathrm{b}} \kappa_{2}\left(E_{\mathrm{b}}^{2}-\left(E^{\star}\right)^{2}\right) E^{\star}, \\
\epsilon \dot{I}_{\mathrm{g} d q}=\epsilon\left(\omega \mathrm{T}_{2}\left(\frac{\pi}{2}\right)-\omega_{\mathrm{b}} \frac{R_{\mathrm{g}}}{L_{\mathrm{g}}} \mathrm{I}\right) I_{\mathrm{g} d q} \\
+\epsilon \frac{\omega_{\mathrm{b}}}{L_{\mathrm{g}}}\left(E_{d q}-\mathrm{T}_{2}(\delta) V_{D Q}\right),
\end{gathered}
$$

where $S=[P, Q]^{\top}$, with $P$ and $Q$ described by 9$]$.

\section{B. The Standard Singular Perturbation Form}

Following step 2 of Section IV-B, with inductive lines interconnecting the GFM inverter to the bus, the dynamics in (21) can be expressed in the standard singular perturbation form as follows:

$$
\begin{aligned}
\dot{\delta} & =\frac{\omega_{\mathrm{b}} \kappa_{1}}{\left(E^{\star}\right)^{2}} \mathrm{e}_{1}^{\top} \mathrm{T}_{2}\left(\psi-\frac{\pi}{2}\right)\left(S^{\star}-S\right), \\
\dot{E}^{\star} & =\frac{\omega_{\mathrm{b}} \kappa_{1}}{E^{\star}} \mathrm{e}_{2}^{\top} \mathrm{T}_{2}\left(\psi-\frac{\pi}{2}\right)\left(S^{\star}-S\right) \\
& \quad+\omega_{\mathrm{b}} \kappa_{2}\left(E_{\mathrm{b}}^{2}-\left(E^{\star}\right)^{2}\right) E^{\star}, \\
\dot{I}_{\mathrm{g} d q} & =\left(\omega \mathrm{T}_{2}\left(\frac{\pi}{2}\right)-\omega_{\mathrm{b}} \frac{R_{\mathrm{g}}}{L_{\mathrm{g}}} \mathrm{I}\right) I_{\mathrm{g} d q}+\frac{\omega_{\mathrm{b}}}{L_{\mathrm{g}}}\left(E_{d q}-\mathrm{T}_{2}(\delta) V_{D Q}\right), \\
\epsilon \dot{I}_{\mathrm{i} d q} & =-\epsilon \frac{\omega_{\mathrm{b}}\left(R_{\mathrm{i}}+K_{\mathrm{P} i}\right)}{L_{\mathrm{i}}} I_{\mathrm{i} d q}+\epsilon \frac{\omega_{\mathrm{b}}}{L_{\mathrm{i}}}\left(K _ { \mathrm { P } i } \left(\rho \left(K_{\mathrm{P} v} \mathrm{e}_{1} E^{\star}\right.\right.\right. \\
& \left.\left.+I_{\mathrm{g} d q}+K_{\mathrm{I} v} \Phi_{d q}-\left(K_{\mathrm{P} v} \mathrm{I}+\frac{\omega}{\omega_{\mathrm{b}}} C \mathrm{~T}_{2}\left(\frac{\pi}{2}\right)\right) E_{d q}\right)\right) \\
& \left.+K_{\mathrm{I} i} \Gamma_{d q}\right), \\
\epsilon \dot{E}_{d q} & =\epsilon \omega \mathrm{T}_{2}\left(\frac{\pi}{2}\right) E_{d q}+\epsilon \frac{\omega_{\mathrm{b}}}{C}\left(I_{\mathrm{i} d q}-I_{\mathrm{g} d q}\right), \\
\epsilon \dot{\Phi}_{d q} & =\epsilon \omega_{\mathrm{b}}\left(1+K_{\mathrm{b}}(\rho-1) K_{\mathrm{P} v}\right) \mathrm{e}_{1} E^{\star} \\
& -\epsilon \omega_{\mathrm{b}}\left(\mathrm{I}+K_{\mathrm{b}}(\rho-1)\left(K_{\mathrm{P} v} \mathrm{I}+\frac{\omega}{\omega_{\mathrm{b}}} C \mathrm{~T}_{2}\left(\frac{\pi}{2}\right)\right)\right) E_{d q} \\
& +\epsilon \omega_{\mathrm{b}} K_{\mathrm{b}}(\rho-1)\left(K_{\mathrm{I} v} \Phi_{d q}+I_{\mathrm{g} d q}\right), \\
\epsilon \dot{\Gamma}_{d q} & =\epsilon \omega_{\mathrm{b}} \rho\left(K_{\mathrm{P} v} \mathrm{e}_{1} E^{\star}+K_{\mathrm{I} v} \Phi_{d q}+I_{\mathrm{g} d q}\right. \\
& \left.-\left(K_{\mathrm{P} v} \mathrm{I}+\frac{\omega}{\omega_{\mathrm{b}}} C \mathrm{~T}_{2}\left(\frac{\pi}{2}\right)\right) E_{d q}\right)-\epsilon \omega_{\mathrm{b}} I_{\mathrm{i} d q}, \\
\rho & =-\varepsilon \ln \left(\exp \left(\frac{-1}{\varepsilon}\right)+\exp \left(-I_{\mathrm{max}} \div \varepsilon \| K_{\mathrm{P} v} \mathrm{e}_{1} E^{\star}\right.\right. \\
& \left.\left.+K_{\mathrm{I} v} \Phi_{d q}+I_{\mathrm{g} d q}-\left(K_{\mathrm{P} v} \mathrm{I}+\frac{\omega}{\omega_{\mathrm{b}}} C \mathrm{~T}_{2}\left(\frac{\pi}{2}\right)\right) E_{d q}\|\|_{2}\right)\right), \\
= & \omega_{\mathrm{b}}+\frac{\omega_{\mathrm{b}} \kappa_{1}}{\left(E^{\star}\right)^{2}} \mathrm{e}_{1}^{\top} \mathrm{T}_{2}\left(\psi-\frac{\pi}{2}\right)\left(S^{\star}-S\right),
\end{aligned}
$$

and when resistive lines interconnect the GFM inverter to the bus, the dynamics in 21) can be expressed in the standard singular perturbation form as follows: 


$$
\begin{aligned}
\epsilon \dot{I}_{\mathrm{i} d q} & =-\epsilon \frac{\omega_{\mathrm{b}}\left(R_{\mathrm{i}}+K_{\mathrm{P} i}\right)}{L_{\mathrm{i}}} I_{\mathrm{i} d q}+\epsilon \frac{\omega_{\mathrm{b}}}{L_{\mathrm{i}}}\left(K _ { \mathrm { P } i } \left(\rho \left(K_{\mathrm{P} v} \mathrm{e}_{1} E^{\star}\right.\right.\right. \\
& \left.\left.+I_{\mathrm{g} d q}+K_{\mathrm{I} v} \Phi_{d q}-\left(K_{\mathrm{P} v} \mathrm{I}+\frac{\omega}{\omega_{\mathrm{b}}} C \mathrm{~T}_{2}\left(\frac{\pi}{2}\right)\right) E_{d q}\right)\right) \\
& \left.+K_{\mathrm{I} i} \Gamma_{d q}\right), \\
\epsilon \dot{E}_{d q} & =\epsilon \omega \mathrm{T}_{2}\left(\frac{\pi}{2}\right) E_{d q}+\epsilon \frac{\omega_{\mathrm{b}}}{C}\left(I_{\mathrm{i} d q}-I_{\mathrm{g} d q}\right), \\
\epsilon \dot{\Phi}_{d q} & =\epsilon \omega_{\mathrm{b}}\left(1+K_{\mathrm{b}}(\rho-1) K_{\mathrm{P} v}\right) \mathrm{e}_{1} E^{\star} \\
& -\epsilon \omega_{\mathrm{b}}\left(\mathrm{I}+K_{\mathrm{b}}(\rho-1)\left(K_{\mathrm{P} v} \mathrm{I}+\frac{\omega}{\omega_{\mathrm{b}}} C \mathrm{~T}_{2}\left(\frac{\pi}{2}\right)\right)\right) E_{d q} \\
& +\epsilon \omega_{\mathrm{b}} K_{\mathrm{b}}(\rho-1)\left(K_{\mathrm{I} v} \Phi_{d q}+I_{\mathrm{g} d q}\right), \\
\epsilon \bar{\Gamma}_{d q} & =\epsilon \omega_{\mathrm{b}} \rho\left(K_{\mathrm{P} v} \mathrm{e}_{1} E^{\star}+K_{\mathrm{I} v} \Phi_{d q}+I_{\mathrm{g} d q}\right. \\
& \left.-\left(K_{\mathrm{P} v} \mathrm{I}+\frac{\omega}{\omega_{\mathrm{b}}} C \mathrm{~T}_{2}\left(\frac{\pi}{2}\right)\right) E_{d q}\right)-\epsilon \omega_{\mathrm{b}} I_{\mathrm{i} d q}, \\
\rho & =-\varepsilon \ln \left(\exp \left(\frac{-1}{\varepsilon}\right)+\exp \left(-I_{\mathrm{max}} \div \varepsilon \| K_{\mathrm{P} v} \mathrm{e}_{1} E^{\star}\right.\right. \\
& \left.\left.+K_{\mathrm{I} v} \Phi_{d q}+I_{\mathrm{g} d q}-\left(K_{\mathrm{P} v} \mathrm{I}+\frac{\omega}{\omega_{\mathrm{b}}} C \mathrm{~T}_{2}\left(\frac{\pi}{2}\right)\right) E_{d q} \|_{2}\right)\right), \\
\omega & =\omega_{\mathrm{b}}+\frac{\omega_{\mathrm{b}} \kappa_{1}}{\left(E^{\star}\right)^{2}} \mathrm{e}_{1}^{\top} \mathrm{T}_{2}\left(\psi-\frac{\pi}{2}\right)\left(S^{\star}-S\right),
\end{aligned}
$$

\section{The Reduced-order Models}

Following step 3 of Section IV-B, when inductive interconnecting lines are used, the reduced-order model is derived by:

(i) Setting $\epsilon=0$ on the left-hand sides of $22 \mathrm{~d}-22 \mathrm{~g}$ ) and setting $\omega=\omega_{\mathrm{b}}$ in 22i to get

$$
\begin{aligned}
0 & =-\frac{\omega_{\mathrm{b}}\left(R_{\mathrm{i}}+K_{\mathrm{P} i}\right)}{L_{\mathrm{i}}} I_{\mathrm{i} d q}+\frac{\omega_{\mathrm{b}}}{L_{\mathrm{i}}}\left(K _ { \mathrm { P } i } \left(\rho \left(K_{\mathrm{P} v} \mathrm{e}_{1} E^{\star}\right.\right.\right. \\
& \left.\left.+K_{\mathrm{I} v} \Phi_{d q}+I_{\mathrm{g} d q}-\left(K_{\mathrm{P} v} \mathrm{I}+C \mathrm{~T}_{2}\left(\frac{\pi}{2}\right)\right) E_{d q}\right)\right) \\
& \left.+K_{\mathrm{I} i} \Gamma_{d q}\right), \\
0 & =\omega_{\mathrm{b}} \mathrm{T}_{2}\left(\frac{\pi}{2}\right) E_{d q}+\frac{\omega_{\mathrm{b}}}{C}\left(I_{\mathrm{i} d q}-I_{\mathrm{g} d q}\right), \\
0 & =\omega_{\mathrm{b}}\left(1+K_{\mathrm{b}}(\rho-1) K_{\mathrm{P} v}\right) \mathrm{e}_{1} E^{\star} \\
& -\omega_{\mathrm{b}}\left(\mathrm{I}+K_{\mathrm{b}}(\rho-1)\left(K_{\mathrm{P} v} \mathrm{I}+C \mathrm{~T}_{2}\left(\frac{\pi}{2}\right)\right)\right) E_{d q} \\
& +\omega_{\mathrm{b}} K_{\mathrm{b}}(\rho-1)\left(K_{\mathrm{I} v} \Phi_{d q}+I_{\mathrm{g} d q}\right), \\
0 & =\omega_{\mathrm{b}} \rho\left(K_{\mathrm{P} v} \mathrm{e}_{1} E^{\star}+K_{\mathrm{I} v} \Phi_{d q}+I_{\mathrm{g} d q}\right. \\
& \left.-\left(K_{\mathrm{P} v} \mathrm{I}+C \mathrm{~T}_{2}\left(\frac{\pi}{2}\right)\right) E_{d q}\right)-\omega_{\mathrm{b}} I_{\mathrm{i} d q}, \\
\rho & =-\varepsilon \ln \left(\exp \left(\frac{-1}{\varepsilon}\right)+\exp \left(-I_{\max } \div \varepsilon \| K_{\mathrm{P} v} \mathrm{e}_{1} E^{\star}\right.\right. \\
& \left.\left.+K_{\mathrm{I} v} \Phi_{d q}+I_{\mathrm{g} d q}-\left(K_{\mathrm{P} v} \mathrm{I}+C \mathrm{~T}_{2}\left(\frac{\pi}{2}\right)\right) E_{d q} \|_{2}\right)\right) .
\end{aligned}
$$

(ii) Noting that $\mathrm{T}_{2}^{-1}\left(\frac{\pi}{2}\right)=-\mathrm{T}_{2}\left(\frac{\pi}{2}\right)$, from 24b and solving for $E_{d q}$ to get

$$
E_{d q}=\frac{1}{C} \mathrm{~T}_{2}\left(\frac{\pi}{2}\right)\left(I_{\mathrm{i} d q}-I_{\mathrm{g} d q}\right),
$$

which is the expression presented in (19b). (iii) Noting that from (24d we have that

$$
\begin{aligned}
\frac{I_{\mathrm{i} d q}}{\rho} & =K_{\mathrm{P} v} \mathrm{e}_{1} E^{\star}+K_{\mathrm{I} v} \Phi_{d q}+I_{\mathrm{g} d q}-\left(K_{\mathrm{P} v} \mathrm{I}\right. \\
& \left.+C \mathrm{~T}_{2}\left(\frac{\pi}{2}\right)\right) E_{d q},
\end{aligned}
$$

and from 24c we have that

$$
\begin{aligned}
0 & =\mathrm{e}_{1} E^{\star}-E_{d q}+K_{\mathrm{b}}(\rho-1)\left(K_{\mathrm{P} v} \mathrm{e}_{1} E^{\star}\right. \\
& \left.+K_{\mathrm{I} v} \Phi_{d q}+I_{\mathrm{g} d q}-\left(K_{\mathrm{P} v} \mathrm{I}+C \mathrm{~T}_{2}\left(\frac{\pi}{2}\right)\right) E_{d q}\right),
\end{aligned}
$$

substituting 26] into 27] to get

$$
0=\mathrm{e}_{1} E^{\star}-E_{d q}+K_{\mathrm{b}}(\rho-1) \frac{I_{\mathrm{i} d q}}{\rho},
$$

substituting (25) into (28) to get

$$
\begin{aligned}
\left(\frac{\rho}{C} \mathrm{~T}_{2}\left(\frac{\pi}{2}\right)\right. & \left.-K_{\mathrm{b}}(\rho-1) \mathrm{I}\right) I_{\mathrm{i} d q} \\
& =\rho\left(\frac{1}{C} \mathrm{~T}_{2}\left(\frac{\pi}{2}\right) I_{\mathrm{g} d q}+\mathrm{e}_{1} E^{\star}\right) .
\end{aligned}
$$

Noting that

$$
\begin{aligned}
& \mathrm{A}_{1}(\rho)=\left(\frac{\rho}{C} \mathrm{~T}_{2}\left(\frac{\pi}{2}\right)-K_{\mathrm{b}}(\rho-1) \mathrm{I}\right)^{-1} \frac{1}{C} \mathrm{~T}_{2}\left(\frac{\pi}{2}\right), \\
& \mathrm{A}_{2}(\rho)=\left(\frac{\rho}{C} \mathrm{~T}_{2}\left(\frac{\pi}{2}\right)-K_{\mathrm{b}}(\rho-1) \mathrm{I}\right)^{-1},
\end{aligned}
$$

and solving for $I_{\mathrm{i} d q}$ using 29) to get

$$
I_{\mathrm{i} d q}=\rho\left(\mathrm{A}_{1}(\rho) I_{\mathrm{g} d q}+\mathrm{A}_{2}(\rho) \mathrm{e}_{1} E^{\star}\right),
$$

which is the expression in $19 \mathrm{a}$.

(iv) Substituting 26 into 24a to get

$$
0=-\frac{\omega_{\mathrm{b}}\left(R_{\mathrm{i}}+K_{\mathrm{P} i}\right)}{L_{\mathrm{i}}} I_{\mathrm{i} d q}+\frac{\omega_{\mathrm{b}}}{L_{\mathrm{i}}}\left(K_{\mathrm{P} i} I_{\mathrm{i} d q}+K_{\mathrm{I} i} \Gamma_{d q}\right),
$$

from where it follows that

$$
\Gamma_{d q}=\frac{R_{\mathrm{i}}}{K_{\mathrm{I} i}} I_{\mathrm{i} d q},
$$

which is the expression presented in (19d).

(v) Substituting 25 into 24d to get

$$
\begin{aligned}
0 & =\rho\left(K_{\mathrm{P} v} \mathrm{e}_{1} E^{\star}-\frac{K_{\mathrm{P} v}}{C} \mathrm{~T}_{2}\left(\frac{\pi}{2}\right)\left(I_{\mathrm{i} d q}-I_{\mathrm{g} d q}\right)\right) \\
& +\rho K_{\mathrm{I} v} \Phi_{d q}+(\rho-1) I_{\mathrm{i} d q}, \\
& =\rho\left(K_{\mathrm{P} v} \mathrm{e}_{1} E^{\star}-K_{\mathrm{P} v} E_{d q}\right)+\rho K_{\mathrm{I} v} \Phi_{d q} \\
& +(\rho-1) I_{\mathrm{i} d q} .
\end{aligned}
$$

Noting that from 28, $\mathrm{e}_{1} E^{\star}-E_{d q}=-K_{\mathrm{b}}(\rho-1) \frac{I_{\mathrm{i} d q}}{\rho}$, and substituting this expression into (32) to get

$$
\begin{aligned}
\rho K_{\mathrm{I} v} \Phi_{d q} & =(\rho-1) K_{\mathrm{P} v} K_{\mathrm{b}} I_{\mathrm{i} d q}-(\rho-1) I_{\mathrm{i} d q}, \\
& =(\rho-1)\left(K_{\mathrm{P} v} K_{\mathrm{b}}-1\right) I_{\mathrm{i} d q},
\end{aligned}
$$

from where it follows that

$$
\Phi_{d q}=\frac{1}{\rho K_{\mathrm{I} v}}(\rho-1)\left(K_{\mathrm{P} v} K_{\mathrm{b}}-1\right) I_{\mathrm{i} d q},
$$

which is the expression presented in 19c.

(vi) Substituting (30) into 25] to get

$$
E_{d q}=\frac{1}{C} \mathrm{~T}_{2}\left(\frac{\pi}{2}\right)\left(-\left(\mathrm{I}-\rho \mathrm{A}_{1}(\rho)\right) I_{\mathrm{g} d q}+\rho \mathrm{A}_{2}(\rho) \mathrm{e}_{1} E^{\star}\right),
$$


substituting 35 into $22 \mathrm{c}$ to get

$$
\begin{aligned}
\dot{I}_{\mathrm{g} d q} & =\omega_{\mathrm{b}}\left(\mathrm{T}_{2}\left(\frac{\pi}{2}\right)\left(\mathrm{I}-\frac{1}{L_{\mathrm{g}} C}\left(\mathrm{I}-\rho \mathrm{A}_{1}(\rho)\right)\right)\right. \\
& \left.-\frac{R_{\mathrm{g}}}{L_{\mathrm{g}}} \mathrm{I}\right) I_{\mathrm{g} d q}+\frac{\omega_{\mathrm{b}}}{L_{\mathrm{g}}}\left(\frac{\rho}{C} \mathrm{~T}_{2}\left(\frac{\pi}{2}\right) \mathrm{A}_{2}(\rho) \mathrm{e}_{1} E^{\star}\right. \\
& \left.-\mathrm{T}_{2}(\delta) V_{D Q}\right),
\end{aligned}
$$

which is the expression presented in $17 \mathrm{c}$.

(vii) Substituting 26] into 22h] to get

$$
\rho=-\varepsilon \ln \left(\exp \left(\frac{-1}{\varepsilon}\right)+\exp \left(\frac{-I_{\max }}{\varepsilon \| I_{\text {id } q / \rho \|_{2}}}\right)\right),
$$

substituting (30) into (37) to get

$$
\begin{aligned}
\rho & =-\varepsilon \ln \left(\exp \left(\frac{-1}{\varepsilon}\right)+\exp \left(-I_{\max } \div \varepsilon \| \mathrm{A}_{1}(\rho) I_{\mathrm{g} d q}\right.\right. \\
& \left.\left.+\mathrm{A}_{2}(\rho) \mathrm{e}_{1} E^{\star} \|_{2}\right)\right)
\end{aligned}
$$

from where it follows that

$$
\begin{aligned}
\rho & =-\varepsilon \ln \left(\exp \left(-\frac{1}{\varepsilon}\right)\right. \\
& \left.+\exp \left(-\frac{I_{\max } \sqrt{C^{2} K_{\mathrm{b}}^{2}(\rho-1)^{2}+\rho^{2}}}{\varepsilon\left\|C \mathrm{e}_{2} E^{\star}+I_{\mathrm{g} d q}\right\|_{2}}\right)\right),
\end{aligned}
$$

which is equivalent to the expression presented in (15). When resistive interconnecting lines are used, the reducedorder model is derived by taking the following additional steps:

(i) Setting $\epsilon=0$ on the left-hand side of (23c), setting $\omega=$ $\omega_{\mathrm{b}}$ on its right-hand side, and substituting 35 into the resulting equation to get

$$
\begin{gathered}
\left(\frac{R_{\mathrm{g}}}{L_{\mathrm{g}}} \mathrm{I}-\mathrm{T}_{2}\left(\frac{\pi}{2}\right)\left(\mathrm{I}-\frac{1}{L_{\mathrm{g}} C}\left(\mathrm{I}-\rho \mathrm{A}_{1}(\rho)\right)\right)\right) I_{\mathrm{g} d q}= \\
\quad+\frac{\rho}{L_{\mathrm{g}} C} \mathrm{~T}_{2}\left(\frac{\pi}{2}\right) \mathrm{A}_{2}(\rho) \mathrm{e}_{1} E^{\star}-\frac{1}{L_{\mathrm{g}}} \mathrm{T}_{2}(\delta) V_{D Q} .
\end{gathered}
$$

(ii) Noting that

$$
\begin{aligned}
& \mathrm{A}_{3}(\rho)=\left(\frac{R_{\mathrm{g}}}{L_{\mathrm{g}}} \mathrm{I}-\mathrm{T}_{2}\left(\frac{\pi}{2}\right)\left(\mathrm{I}-\frac{1}{L_{\mathrm{g}} C}(\mathrm{I}\right.\right. \\
&\left.\left.\left.\quad-\rho \mathrm{A}_{1}(\rho)\right)\right)\right)^{-1} \frac{\rho}{L_{\mathrm{g}} C} \mathrm{~T}_{2}\left(\frac{\pi}{2}\right) \mathrm{A}_{2}(\rho), \\
& \begin{aligned}
\mathrm{A}_{4}(\rho)=-\left(\frac{R_{\mathrm{g}}}{L_{\mathrm{g}}} \mathrm{I}-\mathrm{T}_{2}\left(\frac{\pi}{2}\right)\left(\mathrm{I}-\frac{1}{L_{\mathrm{g}} C}(\mathrm{I}\right.\right. \\
\left.\left.\left.\quad-\rho \mathrm{A}_{1}(\rho)\right)\right)\right)^{-1} \frac{1}{L_{\mathrm{g}}},
\end{aligned}
\end{aligned}
$$

and solving for $I_{\mathrm{g} d q}$ using (40) to get

$$
I_{\mathrm{g} d q}=\mathrm{A}_{3}(\rho) \mathrm{e}_{1} E^{\star}+\mathrm{A}_{4}(\rho) \mathrm{T}_{2}(\delta) V_{D Q},
$$

which is the expression in 20 . 